\title{
1 Plant SYP12 syntaxins mediate an evolutionarily conserved general 2 immunity to filamentous pathogens
}

3

4

\section{Authors}

Hector M. Rubiato ${ }^{1,3, \dagger}$, Mengqi Liu ${ }^{1}$, Richard J. O’Connell ${ }^{2}$ and Mads E. Nielsen ${ }^{1, \uparrow, *}$.

\section{Affiliations}

${ }^{1}$ University of Copenhagen, Faculty of Science, CPSC, Department of Plant and Environmental Sciences, 1871 Frederiksberg C, Denmark

${ }^{2}$ Université Paris-Saclay, INRAE, UR BIOGER, 78850, Thiverval-Grignon, France

${ }^{3}$ Current address: Centre for Plant Biotechnology and Genomics (UPM-INIA), Universidad Politécnica de Madrid Campus de Montegancedo, ,Pozuelo de Alarcón (Madrid), Spain.

${ }^{\dagger}$ These authors contributed equally to this work.

${ }^{*}$ Corresponding author

\section{Abstract}

Filamentous fungal and oomycete plant pathogens that invade by direct penetration through the leaf epidermal cell wall cause devastating plant diseases. Plant pre-invasive immunity towards nonadapted filamentous pathogens is highly effective and durable. Pre- and post-invasive immunity correlates with the formation of evolutionarily conserved and cell-autonomous cell wall structures, named papillae and encasements, respectively. Yet, it is still unresolved how papillae/encasements are formed and whether these defense structures prevent pathogen ingress. Here we show that in Arabidopsis, the two closely related members of the SYP12 clade of syntaxins (PEN1 and SYP122) are indispensable for the formation of papillae and encasements. Moreover, loss-of-function mutants were hampered in pre-invasive immunity towards a range of phylogenetically distant nonadapted filamentous pathogens, underlining the versatility and efficacy of this defense. Complementation studies using SYP12s from the early diverging land plant, Marchantia polymorpha, showed that the SYP12 clade immunity function has survived 470 My of independent evolution. These results suggest that ancestral land plants evolved the SYP12 clade to provide a 
broad and durable pre-invasive immunity to facilitate their life on land, and pave the way to a better understanding of how adapted pathogens overcome this ubiquitous plant defense strategy.

\section{Introduction}

In response to attack by filamentous pathogens, plants assemble localized pre-invasive papillae and post-invasive encasements at sites of attempted cell entry (Figure 1-figure supplement 1A-B) (Hückelhoven and Panstruga, 2011). These conserved defense structures are thought to contain antimicrobial cargo that provide effective and durable immunity against diverse filamentous pathogens, and fossil evidence suggests that these structures appeared very early in the evolution of land plants (O’Connell and Panstruga, 2006; Krings et al., 2007; Overdijk et al., 2016; Hansen and Nielsen, 2018). However, although their frequent association with resistance to non-adapted pathogens is well-known, direct evidence that papillae/encasements contribute to immunity against these pathogens is still lacking. The discovery that the secretory syntaxin PEN1 is required for the timely formation of papillae to hamper penetration by non-adapted powdery mildew fungi highlighted the key role played by membrane trafficking in plant immunity (Collins et al., 2003; Nielsen et al., 2012; Nielsen and Thordal-Christensen, 2013). PEN1 (also referred to as syntaxin of plants 121 or SYP121) is a Qa-SNARE primarily located at the plasma membrane. On the other hand, the ARF-GEF, GNOM, regulates recycling of PEN1 between the plasma membrane and the trans-Golgi network, where it is needed for a fast papilla response (Nielsen et al., 2012). Accordingly, PEN1 is thought to mediate membrane fusion both at the plasma membrane and at the trans-Golgi network. The ROR2 syntaxin in barley is orthologous to PEN1 (Collins et al., 2003), suggesting that the pre-invasive immunity dependent on PEN1 or ROR2 was present in early angiosperms before the divergence of monocots and dicots, spanning some 140 million years (My) of evolution. Focal accumulation of GFP-PEN1 at attack sites in response to Blumeria graminis f.sp. hordei $(B g h)$ is also seen for ROR2 in barley and highlights a likely conserved functionality in plant defense against powdery mildews (Bhat et. al, 2005). The strong extracellular accumulation of GFP-PEN1 signal localized to fungal attack sites can be explained by the secretion of extracellular vesicles, also known as exosomes, which accumulate to a high degree in both papillae and encasements (An et al., 2006; Meyer et al., 2009; Nielsen et al., 2012). While exosomes are suggested to contain miRNAs directed against the invading pathogen, their topology makes it difficult to associate syntaxin functionality (Meyer et al., 2009; Hansen and Nielsen, 2018). GFP- 
PEN1 is generally considered a valid exosomal marker yet the biogenesis pathway of PEN1-labeled exosomes remains unclear (Rutter and Innes, 2017). Loss of PEN1 or ROR2 delays, but does not prevent, the papilla response upon attack by the barley powdery mildew fungus Bgh in Arabidopsis or barley, respectively (Assaad et al., 2004; Böhlenius et al., 2010). In contrast, the deposition of encasements around developing intracellular pathogenic structures (IPS) is unaffected by the loss of PEN1 (Wen et al., 2011; Nielsen et al., 2017). Furthermore, although many other filamentous pathogens also penetrate directly through the plant epidermal cell wall, the PEN1- and ROR2dependent immunity appears dedicated towards the haustorium-forming powdery mildew and rust fungi (Collins et al., 2003; Jarosch et al. 2005; Lipka et al., 2005; Loehrer et al., 2008; Hoefle et al., 2009). Thus, the molecular mechanisms underlying papilla/encasement formation, as well as their role in general plant pre- and post-invasive immunity towards other filamentous pathogens, remain obscure.

PEN1 and ROR2 belong to the SYP12 clade of secretory syntaxins, which first appears in embryophytes and is conserved in all land plants (Slane et al., 2017). Consequently, the appearance of the SYP12 clade was proposed to play a key role in the terrestrialization of plants by enabling specialization of the secretory pathway (Sanderfoot, 2007). This is supported by the fact that four of the five SYP12 clade members in Arabidopsis function in specialized forms of polarized secretion, these being pre-invasive immunity towards powdery mildew fungi (PEN1), root hair tip growth (SYP123), and pollen tube tip growth (SYP124 and SYP125) (Collins et al., 2003; Slane et al., 2017; Ichikawa et al., 2014). Recently, PEN1 and SYP122, which is the closest homologue of PEN1, were suggested to mediate distinct but complementary secretory pathways during vegetative plant growth (Waghamare et la., 2018). Indeed, syp122 mutants show an altered cell wall composition but in contrast to pen1 mutants there is no effect on the pre-invasive immunity towards Bgh (Assaad et al., 2004). Interestingly, the pen1 syp122 double mutant is autoimmune, developing a severe necrotic phenotype and accumulating the defense hormone salicylic acid (Assaad et al., 2004; Zhang et al., 2007, 2008). However, prior to the onset of necrosis, pen1 syp122 double mutant plants are indistinguishable from wild-type plants. This underlines that PEN1 and SYP122 likely mediate a highly specialized form of secretion whereas general secretion relies on the evolutionarily ancient Qa-SNARE SYP132 (Park et al., 2018; Karnahl et al., 2018). The development of necrotic lesions in pen1 syp122 double mutant plants is markedly delayed when the accumulation of salicylic acid is hampered (Zhang et al., 2007, 2008). Accordingly, the penl 
syp122 double mutant autoimmune phenotype was suggested to result from activation of nucleotide-binding leucine-rich repeat receptors (NLRs), immune sensors that recognize pathogen effectors, directly or indirectly, which leads to a programmed cell death response (Wang et al., 2019a; Wang et al., 2019b; Horsefield et al., 2019; Wan et al., 2019). In support of this, mutations in the deubiquitinase AMSH3 that impairs the cell death reaction caused by activation of coiled-coil (CC)-NLRs, also suppresses the autoimmune phenotype of the penl syp122 double mutant (Schultz-Larsen et al., 2018). The autoimmune phenotype shows that while PEN1 and SYP122 are likely to have separate functions in the pre-invasive immunity towards $B g h$, the two syntaxins also share an as-yet unresolved function which is likely related to defense and not general development.

Here we show that the formation of papillae and encasements in Arabidopsis requires either of the two SYP12 clade members, PEN1 and SYP122, because plants lacking both syntaxins are completely devoid of both types of defense structure. We show that PEN1 and SYP122 provide preand post-invasive immunity not only against the powdery mildew $B g h$ but also against distantlyrelated filamentous pathogens that invade host epidermal cells, namely the fungus Colletotrichum destructivum and the oomycete Phytophthora infestans. Complementation studies show that SYP12A from Marchantia polymorpha functions and behaves like SYP122 in Arabidopsis, thereby revealing a conserved ancestral mechanism. We conclude that papilla and encasement formation is mediated by a specialized function of the SYP12 clade of syntaxins and that these defense structures correlate with a broad and effective resistance towards filamentous pathogens that penetrate the epidermal cell layer. Moreover, we suggest that early land plants evolved the SYP12 clade of secretory syntaxins to provide a durable immunity that helped plants move on to land and possibly shape mutualistic plant-fungus interactions.

\section{Results}

The role of PEN1 in timely papilla deposition in response to $B g h$ attack prompted us to investigate the involvement of other syntaxins in pre-invasive immunity, notably SYP122 that shares a currently unknown function with PEN1. This shared function is apparent from the autoimmune lesion-mimic phenotype of the pen1 syp122 double mutant (Assaad et al., 2004; Zhang et al., 2007, 2008). Yet, during the first $\sim$ two weeks of growth, the pen1 syp122 mutant develops no visible 
symptoms, leaving a short window in which to study the interaction with $B g h$ before the onset of necrosis. From analysis of unattacked plants, we found that the pen1 syp122 mutant developed spontaneous callose deposits despite having a wild-type like appearance (Figure 1A-B). Callose is a polysaccharide (beta-1,3-glucan) secreted in response to various biotic and abiotic stresses and is a major constituent of papillae and encasements. Although the deposition of callose is not required to block the penetration event by Bgh per se, it serves as a reliable visual marker for easy detection of papillae and encasements (Ellinger et al., 2013). We found that in response to attack by $B g h$, plants lacking PEN1 and SYP122 were unable to form papillae at sites of unsuccessful attack by fungal appressoria, as visualized by detection of callose (Figure 1C-D). Surprisingly, while the appressorial germtube did not induce a papilla response in pen1 syp122 mutants, we observed large callosic deposits induced by the non-invasive primary germ tube, which were not observed in any other genetic background (Figure 1D, F-G, Figure 1-figure supplement S1A). Thus, SYP122 seems to play a complementary role to PEN1 in papilla formation upon attack by $B g h$. However, despite being unable to form a papilla at the attempted entry site, the pen 1 syp 122 mutant remains capable of generating focused depositions of callose elsewhere and seems to be highly sensitive to signals released by $B g h$.

In response to a successful penetration attempt by $B g h$, the host cell initiates post-invasive immunity, where an encasement forms as an extension of the penetrated papilla (Figure 1-figure supplement 1B). The encasement expands and, eventually, completely encloses the IPS and likely prevents the pathogen from proliferating. Previous observations have shown that although pen1 mutants display a delayed papilla formation response to attack by $B g h$, these plants seem unaffected in their ability to form encasements when successfully penetrated (Assaad et al., 2004; Wen et al., 2011; Nielsen et al., 2017). In contrast to our observations of unsuccessful penetration sites, the successful penetration of penl sypl22 cells often induced a strong but diffuse, unfocused accumulation of callose at the fungal entry site (Figure 1E-G, Figure 1 - video 1-2). Interestingly, we did not observe any encasement-like structures. Instead, the callosic deposits in the pen1 syp122 mutant were superficial and did not extend inwards from the outer surface of the host cell enveloping the growing IPS. This would suggest that the penetration event by $B g h$ triggers a strong callose response but formation of the encasement is dependent on a functional overlap of the PEN1 and SYP122 syntaxins. Furthermore we tested the adapted powdery mildew Golovinomyces orontii (G.orontii) which also induces encasement formation, although at a later stage and less frequently than Bgh. For G. orontii, IPS formation seemed unaffected in pen1 syp122 and no encasements 
were found. Interestingly, successful penetration by $G$. orontii did not induce the strong, diffuse callose response described for Bgh (Figure 1-figure supplement 1C-D, Figure 1 - video 3-4).

The lack of papillae and encasements in the pen1 syp122 mutant, prompted us to investigate the secretion of exosomes in response to $B g h$ attack. We speculated that the plant exosomal marker TET8-GFP (TETRASPANIN 8), which accumulates at sites of attack by Botrytis, would also accumulate in response to attack by Bgh (Boavida et al., 2013; Cai et al., 2018). In unattacked epidermal cells of wild-type plants, we found TET8-GFP localized mainly on the plasma membrane (Figure 2A). TET8-GFP signal focally accumulated in response to successful penetration by $B g h$ and seems a reliable marker for the encasement (Figure 2B). In unattacked epidermal cells of the pen1 syp122 mutant, the TET8-GFP localization was similar to that seen in wild-type plants whereas successful penetration by Bgh did not induce focal accumulation of TET8-GFP (Figure 2CD, Figure 2 - video 1-2). Thus, the general localization of TET8-GFP was not affected in the pen1 syp122 mutant. Only in the event of fungal attack where TET8-GFP is transported to the infection site in wild-type plants, this did not occur in the double mutant, supporting the idea that PEN1 and SYP122 play a specific role in pre- and post-invasive immunity.

We noticed that the spontaneous callose deposits formed in the lesion-mimic pen1 syp122 mutant, made it difficult to compare pre- and post-invasive immunity responses during attack by $B g h$. Furthermore, successful penetration of epidermal cells in penl syp122 by Bgh, and even G. orontii, resulted in a fast-developing cell death response which would likely compromise encasement formation. To overcome the difficulties of working with the penl sypl22 mutant, we made use of the partially rescued triple mutant, fmol penl syp122 (Zhang et al., 2008). Flavin-dependentmonooxygenase1 (FMO1) enables Arabidopsis plants to generate N-hydroxypipecolic acid, which plays a central role in pathogen-inducible plant immunity (Hartman et al., 2018). Similar to introducing a number of SA-signalling mutations, the loss of FMO1 clearly relieves the downstream effects of the pen1 syp122 lesion-mimic mutant (Figure 3-figure supplement 1A-B). However, importantly, these mutations do not affect pre-invasive immunity towards $B g h$, thereby clearly separating the two phenotypes mechanistically (Zhang et al., 2007 and this work). Moreover, fmol pen1 syp122 plants did not display the large callosic deposits induced by the noninvasive primary germ tube. To ensure that the autoimmune phenotype of fmol pen 1 syp 122 would not compromise fungal development, we first tested G.orontii. During the initial 48 hours after inoculation, we found that formation of the IPS and secondary hyphae in fmol pen1 sypl22 was indistinguishable from the fmol control plants (Figure 3-figure supplement 1C-D). In response to 
attack by $B g h$, we found that fmol plants formed papillae at the site of attack which were identical to wild-type as visualized by detection of callose (Figure 3A-C, Figure 3-figure supplement 2A-D). Instead, plants lacking PEN1 and SYP122 were unable to form discrete papillae at sites of unsuccessful fungal attack. To support these findings, we also tested the ability of these plants to accumulate papillary $\mathrm{H}_{2} \mathrm{O}_{2}$ in response to attack by $B g h$ using DAB (Thordal-Christensen et al., 1997). Similar to the staining of callose, the accumulation of $\mathrm{H}_{2} \mathrm{O}_{2}$ is used as a convenient marker of the defense structure. In accordance with our observations on callose deposition, we found that fmol pen1 syp122 plants failed to accumulate papillary $\mathrm{H}_{2} \mathrm{O}_{2}$ (Figure 3D-F). Thus, these results confirmed that plants lacking PEN1 and SYP122 failed to form papillae at sites of attack by Bgh.

Similar to the papilla response, we found that fmol mutants reacted like wild-type plants in response to successful penetration by $B g h$, as visualized by the detection of callose encasements around the IPS (Figure 4A-C, Figure 4-figure supplement 1A-D). In stark contrast to this, fmol pen1 syp122 plants were unable to create an encasement around the developing IPS when penetrated by $B g h$. To rule out the possibility that the lack of these defense structures is due to a host cell death response, dead cells stained by Trypan blue were excluded from our observations. Similar to our observations on papilla formation, we also assessed the ability of these plants to accumulate $\mathrm{H}_{2} \mathrm{O}_{2}$ in response to successful penetration by $B g h$ using DAB. We found that in fmol pen1 syp122 plants, successful penetration by Bgh induced a diffuse, superficial accumulation of $\mathrm{H}_{2} \mathrm{O}_{2}$ but we did not observe encasement-like structures (Figure 4D-E). This supported our finding that plants lacking PEN1 and SYP122 failed to form encasements at sites of attack. To verify the requirement for PEN1 and SYP122 in forming papillae and encasements, we included observations of pad4 sid2 pen1 syp122 and amsh3 pen1 syp122 mutants, where, similar to fmol, the autoimmune phenotype of pen1 syp122 is attenuated (Zhang et al., 2008; Schultz-Larsen et al., 2018). As expected, fungal development and host cell responses in these lines were similar to that observed in fmol pen1 syp122 plants (Figure 4-figure supplement 2, Figure 4 - video 1-8). As SYP122 appears to have a significant, albeit less important, role in papilla and encasement formation, we wondered if the complete absence of these defense structures would lead to an increase in penetration frequency as compared to the delayed papilla response described for the penl mutant. We found a significant increase in fungal penetration frequency on fmol pen1 syp122 plants when compared to penl single and fmol pen 1 double mutant plants (Figure 4F). This supports our previous finding of a minor, but significant PEN1-independent contribution to pre-invasive immunity that relates to proper formation of the encasement (Nielsen et al., 2017). Taken together, these observations show 
that the $B g h$-induced formation of papillae and encasements at attack sites is dependent on a functional overlap between the PEN1 and SYP122 syntaxins.

To further dissect the overlapping functions of PEN1 and SYP122 in immunity, we tested host cell responses to another, non-adapted fungal pathogen, namely $C$. destructivum (an ascomycete fungal pathogen causing alfalfa anthracnose disease). The initial invasion strategy of $C$. destructivum is very similar to that of Bgh (Latunde-Dada et al., 1997). Nevertheless, while host cell responses include papilla formation, the highly effective pre-invasive immunity of Arabidopsis towards nonadapted Colletotrichum species such as C. destructivum does not require PEN1 (Shimada et al., 2006; Yang et al., 2014). Moreover, attack by $C$. destructivum did not induce accumulation of GFPPEN1, GFP-SYP122 or TET8-GFP at sites of attempted penetration (Figure 5-figure supplement 1A-C). Nonetheless, we found that plants lacking both PEN1 and SYP122 showed a dramatic decrease in the ability to form papillae at sites of unsuccessful penetration (Figure 5A-C). In contrast to $B g h$, the host cell response to penetration by $C$. destructivum only rarely resulted in the formation of a detectable encasement. Nevertheless, penetrated host cells did respond by accumulating callose in and around the site of penetration. In fmol penl syp122, the responses varied from no detectable callose to a faint diffuse accumulation of callose at the penetration site (Figure 5D-E, Figure 5-figure supplement 1D-E). Moreover, the lack of host cell responses correlated with a remarkable increase in penetration frequency by $C$. destructivum on fmol pen 1 syp122 plants (Figure 5F, Figure 5-figure supplement 1F-G). Thus, pre-invasive immunity towards C. destructivum requires a syntaxin function shared by PEN1 and SYP122 and this correlates with the lack of defense structure formation in response to attack.

Finding that PEN1 and SYP122 facilitate a pre-invasive immunity that extends to a fungal pathogen other than powdery mildews, we speculated that this immunity could be a general defense mechanism effective against an even wider range of direct penetrating filamentous pathogens. One such pathogen is $P$. infestans (the potato blight pathogen), which, as an oomycete, is thought to have evolved completely independently of true fungi (Lévesque, 2011). Similar to the above observations for $C$. destructivum, pre-invasive immunity towards P. infestans in Arabidopsis does not rely on a functional PEN1 (Lipka et al., 2005). Instead, Rodriguez-Furlán et al. (2016) reported that loss of the root-hair specific SYP123 affects the penetration rates by P. infestans. However, SYP123 was suggested to regulate rhizobacterial priming of induced systemic resistance and is unlikely to be directly involved in the pre-invasive response in leaves. We observed that attempted penetration by $P$. infestans did not lead to accumulation of either GFP-PEN1, GFP-SYP122 or 
TET8-GFP at the site of attack (Figure 6-figure supplement 1A-C). As expected, penetration attempts by $P$. infestans incited papilla formation in all genotypes, except for fmol pen1 syp122 (Figure 6A-C). Successful penetration by $P$. infestans was often followed by host cell death. Nevertheless, we found that host cells expressing PEN1 and/or SYP122 could initiate a strong accumulation of callose and form an encasement around the IPS. In the fmo1 pen1 syp122 triple mutant, the penetrated cell, as well as neighboring cells, responded with a diffuse callose accumulation but encasement of the IPS was not seen (Figure 6D-E). Similar to our observations with $C$. destructivum, fmol pen1 syp122 plants displayed elevated penetration frequencies when attacked by $P$. infestans (Figure 6F, Figure 6-figure supplement 1D). Surprisingly, we could not detect an increase in penetration events by $P$. infestans in the syp123 mutant, even when in combination with pen1. Taken together, these findings show that PEN1 or SYP122 are required for papilla and encasement responses, which mediate immunity towards these phylogenetically distant, non-adapted filamentous pathogens. Moreover, it is striking that the functionality of PEN1 and SYP122 in immunity does not correlate with the ability of these syntaxins to visibly accumulate at attack sites.

PEN1 and SYP122 belong to the SYP12 clade of secretory syntaxins, which evolved during plant terrestrialization and is conserved in all land plants (Sanderfoot, 2007; Slane et al., 2017). To evaluate whether the immunity function of the SYP12 clade is also evolutionarily conserved among land plants, we investigated the response of the early diverging land plant Marchantia to attack by non-adapted filamentous pathogens. Consistent with previous findings, the germinating spores of $B g h$ were not able to properly differentiate a penetration hypha or appressorium on Marchantia thalli (Figure 7-figure supplement 1A; Takikawa et al., 2013). Similarly, most spores of P. infestans germinating on Marchantia seemed unable to identify a host cell and direct an attack. Nonetheless, occasional sites of attempted and successful penetrations were detected, to which the host cell responded by forming papillae and encasement-like defense structures, respectively (Figure 7A, Figure 7-figure supplement 1B). Thus, neither Bgh nor P. infestans were suitable for studying nonhost interactions in Marchantia. In contrast, C. destructivum spores germinated and developed characteristic darkly melanized appressoria on the thallus surface. In response to attack, Marchantia epidermal cells formed callose-containing papillae similar to those found in Arabidopsis (Figure 7B). However, we never detected successful penetration of Marchantia cells by C. destructivum. A previous report that the Marchantia syntaxin MpSYP13B accumulates in response to colonization by $P$. palmivora prompted us to test whether candidate MpSYPs also accumulate in response to $C$. 
destructivum (Carella et al., 2018). However, despite inducing papillae, attack by C. destructivum did not induce focal accumulation of any of the four MpSYPs tested (Figure 7C-F; Kanazawa et al., 2016). Thus, the cellular responses of Marchantia to $C$. destructivum were similar to those that we observed in Arabidopsis.

In contrast to PEN1 and SYP122 in Arabidopsis, MpSYP12A seems to be essential in Marchantia, thereby precluding the possibility for studying pre-invasive immunity in knock-out lines (Kanazawa et al., 2020). Instead, to evaluate whether the immunity function of the SYP12 clade is evolutionarily conserved among land plants, we introduced GFP-fused versions of the two Marchantia SYP12s (i.e. MpSYP12A and MpSYP12B) into the Arabidopsis pen1 syp122 mutant. GFP-MpSYP12A fully suppressed the necrotic and dwarfed phenotypes of pen1 syp122 plants, while GFP-MpSYP12B only partially suppressed these phenotypes (Figure 8-figure supplement 1A-B). In contrast, expression of either of the two SYP13 clade members, MpSYP13A and MpSYP13B, failed to rescue the pen1 syp122 mutant. This suggests that MpSYP12A shares the PEN1/SYP122 overlapping function and that MpSYP12B does so incompletely. Because MpSYP12A complements the growth phenotype of pen1 syp122 at the macroscopic level, we decided to test how these plants react to attack by Bgh. We found that MpSYP12A completely, and MpSYP12B partially, restored both papilla and encasement responses (Figure 8A-B, Figure 8figure supplement 2, Figure 8-figure supplement 3). As explained above, the papillary accumulation of GFP-PEN1 in response to attack by $\mathrm{Bgh}$ is also seen for ROR2 in barley and highlights a likely conserved functionality in plant defense against powdery mildews (Bhat et. al, 2005). In contrast, neither GFP-SYP122 nor the two GFP-MpSYP12s accumulated in papillae at sites of attempted penetration (Figure 8C, Figure 8-figure supplement 4). However, all the tested SYPs accumulated in the encasement matrix at sites of successful penetration (Figure 8D, Figure 8-figure supplement 5). Interestingly, pre-invasive immunity towards $B g h$ was not restored by GFP-MpSYP12A. Instead, the penetration frequency of $B g h$ was similar to that of plants expressing GFP-SYP122 (Figure 8E). Thus, MpSYP12A resembles SYP122, and not PEN1, both in its localization and functionality. In support of this, GFP-MpSYP12A fully restored immunity towards both $P$. infestans and $C$. destructivum (Figure 8F, Figure 8-figure supplement 6A-B). Also, when tested with the adapted filamentous pathogens $G$. orontii and $C$. higginsianum, penetration frequencies were similar to plants expressing PEN1 and SYP122 (Figure 8-figure supplement 6C-D). As described for PEN1 and SYP122, focal accumulation of GFP-MpSYP12A or GFP-MpSYP12B was not observed at 
unsuccessful attack sites by either $C$. destructivum or P. infestans (Figure 8-figure supplement 7). Taken together, these results reveal a conserved SYP12 clade functionality that has survived 470 My of independent evolution. Moreover, our findings suggest that the PEN1-dependent immunity towards powdery mildew fungi evolved at a later stage of land plant evolution.

\section{Discussion}

We have revealed a highly conserved role for the SYP12 clade of plant syntaxins in mediating the formation of pre- and post-invasive defense structures and provide immunity to highly diverged filamentous pathogens. Arabidopsis plants lacking both PEN1 and SYP122 were incapable of forming papillae and encasements in response to attack by the non-adapted pathogens $B g h, C$. destructivum and $P$. infestans, as based on staining for callose and $\mathrm{H}_{2} \mathrm{O}_{2}$, resulting in highly elevated penetration frequencies. Instead, these plants responded to attack with diffuse and unfocused accumulations of callose and $\mathrm{H}_{2} \mathrm{O}_{2}$. It is noteworthy that although the pen1 syp122 double mutant lacks these defense structures, epidermal cells are still able to respond to pathogenderived signals in a polarized fashion, as seen in responses to the non-penetrative primary germ tube of $B g h$. This underlines that neither the general ability to secrete callose, generate $\mathrm{H}_{2} \mathrm{O}_{2}$, nor the underlying mechanism needed for polarized secretion are dependent on PEN1 and SYP122. Instead, we suggest that the PEN1/SYP122-dependent papillae and encasements are defense structures that enable a focused secretion, specifically aimed at blocking the ingress of filamentous pathogens. In support of this, knock-down of StSYR1 in potato, a homolog of PEN1, results in reduced papilla formation in response to $P$. infestans (Eschen-Lippold et al., 2012). A more indirect role of syntaxins in pre-invasive immunity is the regulation of rhizobacterial priming of induced systemic resistance by the root-hair specific SYP123 (Rodriguez-Furlán et al. 2016). The induction of systemic resistance could affect the speed by which PEN1/SYP122 dependent papillae/encasements form in response to attack. However, as we failed to see an effect of SYP123, we could not pursue this question further. We are unsure of the reason for this discrepancy between our results and those reported by Rodriguez-Furlán et al. (2016), but we speculate that differences in the soil composition and microbiome could play a role in this. Instead, we have shown here that loss of papillae/encasements correlates with the loss of general pre-invasive immunity. Yet, it is difficult to explain how these cell wall depositions would prevent invasion by pathogens secreting cell wall degrading enzymes. Also, we find it unlikely that accumulation of callose, $\mathrm{H}_{2} \mathrm{O}_{2}$, syntaxins or even 
TET8 would have a direct effect on the pathogen. This is supported by our observations that neither PEN1, SYP122 nor TET8 focally accumulate in response to attack by $C$. destructivum or $P$. infestans, despite the formation of papillae. Instead our findings reinforce the idea that papillae and encasements serve as defense structures that contain a complex mixture of exosomes, toxic metabolites and/or antimicrobial enzymes and peptides that mediate immunity (Kwon et al., 2008). It is likely that these cargo molecules are delivered in a PEN1- and SYP122-dependent manner to the site of attack to form papillae/encasements and thus prevent pathogen ingress.

Previous studies on the interaction between Arabidopsis and $B g h$ have revealed that pre-invasive immunity correlates with the timely formation of papillae. This fast response likely requires the recycling of papilla material in a process involving PEN1 and GNOM (Nielsen et al., 2012). In contrast, although SYP122 also locates to the plasma membrane and interacts with the same SNARE partners as PEN1, syp122 mutants show a wild-type response to Bgh (Assaad et al., 2004; Pajonk et al., 2008). Previous studies have shown that PEN1 and SYP122 mediate the secretion of distinct cargo subsets, which may explain their differing contributions to pre-invasive immunity (Waghmare et al., 2018). Based on the work presented here, it is now evident that PEN1 and SYP122 functionally overlap in the formation of papillae and encasements. This could be explained by PEN1 serving two functions in pre-invasive immunity. The first mediates a fast mobilization of papilla material, while the second function is shared with SYP122 and contributes to a more general papilla and encasement response to filamentous pathogens (Figure 9). An alternative explanation would be that although redundant with SYP122, PEN1 somehow plays a more significant role in pre-invasive immunity against $B g h$. The fast mobilization of papilla material is likely related to the ability of PEN1 to shuttle between the plasma membrane and trans-Golgi network, which is less prominent for SYP122 (Hansen and Nielsen, 2018; Nielsen and Thordal-Christensen, 2012; Nielsen and Thordal-Christensen, 2013). Consequently, PEN1, and less so SYP122, could function at the trans-Golgi network, receiving vesicles from the plasma membrane that mediate the fast GNOMdependent recycling of papilla material, warding off the powdery mildew fungus. We envisage that the redundant function of PEN1 and SYP122 is at the plasma membrane, where either of the two syntaxins receive the membrane material and vesicular cargo required for papilla/encasement formation. In contrast to the fast-acting, PEN1-dependent papilla response explained above, the slow-forming papilla uses either PEN1 or SYP122 already present at the site of attack in the plasma membrane and does not necessitate a fast recycling of the syntaxin itself. This could help to explain 
why PEN1 and SYP122 do not accumulate at sites of attack by $C$. destructivum and $P$. infestans although both syntaxins clearly mediate pre-invasive immunity. The pathway that delivers cargo for the slow-forming papilla is also likely to be involved in delivering cargo for the encasement, because the formation of neither is affected by the lack of PEN1. Therefore, we speculate that the differences in papilla content based on observations of GFP-PEN1, GFP-SYP122 and TET8-GFP, result from the involvement of distinct pathways for delivering cargo vesicles to the papilla. Alternatively, as the accumulation of some papilla cargos are triggered by only a subset of pathogens, the host cell might be able to differentiate the response according to the attacker. Nonetheless, these pathways share a common requirement for PEN1 or SYP122 to mediate vesicle fusion with the plasma membrane at pathogen attack sites. In addition, because some spores fail to penetrate, even in the complete absence of papillae and encasements, pre-invasive immunity towards filamentous pathogens could also involve other molecular pathways that act independently of PEN1 and SYP122. In this regard, pre-invasive immunity mediated by PEN2 and PEN3, as well as the resistance gained by loss of MLO, are of particular interest, since both pathways seem to function independently of PEN1 (Lipka et al., 2005; Stein et al., 2006; Kuhn et al., 2017). It remains to be elucidated if these pre-invasive immunity pathways also function independently of SYP122.

The SYP12 clade of plant secretory syntaxins is thought to have evolved during colonization of the land and is conserved in all land plants so far examined (Slane et al., 2017). Because terrestrialization presented enormous challenges to plants, the SYP12 clade was suggested to have acquired specialized roles in secretion needed to facilitate this transition (Sanderfoot, 2007). This is consistent with the previously identified functions of PEN1 (powdery mildew resistance), SYP123 (root hair tip growth) and, SYP124 and SYP125 (pollen tube tip growth) all being associated with specialized forms of polarized secretion (Collins et al., 2003; Slane et al., 2017; Ichikawa et al., 2014). In addition, PEN1 promotes $\mathrm{K}^{+}$uptake by direct interaction with the RYxxWE motif found in a subset of Kv channels (Karnik et al., 2017). However, powdery mildews, roots hairs and pollen tubes did not exist until long after the onset of plant terrestrialization. Also, the interaction motifs needed for $\mathrm{Kv}$ channel interaction, is restricted to vascular plants (Karnik et al., 2017). Therefore, this knowledge gives little insight into the original function of the SYP12 clade. Our discovery that SYP12A from Marchantia can complement SYP122, but not PEN1, in Arabidopsis reveals a conserved syntaxin functionality spanning $470 \mathrm{My}$ of independent evolution. In accordance with this, MpSYP12A showed a localization behavior identical to that of SYP122. Therefore, the 
409

410

411

functionality of the original SYP12 clade syntaxins is likely to have been similar to that of MpSYP12A and SYP122. At a later stage of plant evolution, PEN1 has acquired an additional specialization needed for powdery mildew resistance, which could explain its distinctive subcellular localization (Nielsen and Thordal-Christensen, 2012; 2013). Interestingly, in Marchantia, MpSYP12A locates to the plasma membrane and seems vital for cell plate formation whereas MpSYP12B locates to a type of oil body unique to liverworts (Kanazawa et al., 2016; 2020). This indicates yet another functional specialization of the SYP12 clade similar to that which occurred in Arabidopsis.

We suggest that MpSYP12A and SYP122 represent the original SYP12 clade functionality in land plants, which provides a highly conserved and effective broad-spectrum immunity towards filamentous pathogens. Before plant terrestrialization, the land was already colonized by filamentous fungi that were able to degrade cell walls and to utilize living or dead plant tissue as a nutrient source (Chang et al., 2015). Recent findings suggest that even before terrestrialization, plants used nucleotide-binding leucine-rich repeat receptors (NLRs) to activate their defense responses (Gao et al., 2018). Activation of plant NLRs leads to a fast, programmed cell death response, which does not provide immunity against fungi growing on dead or dying plant tissue (Wang et al., 2019a; Wang et al., 2019b; Horsefield et al., 2019; Wan et al., 2019). Instead, the papilla/encasement defense structures would have conferred an effective defensive barrier against attack by the early saprophytic filamentous fungi already present on the land. Moreover, it is generally accepted that plant colonization of the land was aided by, or dependent on, mycorrhizalike fungi (Pirozynskjk et al., 1975; Redecker et al., 2000; Heckman et al., 2001). These mutualistic interactions are thought to have resulted from ancestral land plants being able to 'tame' early saprophytic filamentous fungi (Chang et al., 2015; Berbee et al., 2017). In this context, hyphal encasement may have provided a tool for plants to restrict and manipulate the intracellular growth of these fungi. We envisage that the SYP12 syntaxins enabled early land plants to regulate fungal entry and colonization, and that over time this lead to the mutually beneficial interactions that facilitated terrestrialization.

Adapted filamentous pathogens are able to overcome pre-invasive immunity in their respective host-plants, but not in other plant species. Our finding that plants could rely on a common membrane trafficking pathway to block pathogen entry should lead to new insights into how successful pathogens defeat this immunity by means of effector proteins (Jones et al., 2016). A future goal will be to identify the membrane trafficking targets of such effectors and to exchange 
those between hosts and non-hosts to generate a pre-invasive immunity that pathogens cannot overcome.

\section{References}

An Q, Hückelhoven R, Kogel KH, van Bel AJ., Multivesicular bodies participate in a cell wallassociated defence response in barley leaves attacked by the pathogenic powdery mildew fungus. Cellular Microbiology. 8, 1009-1019 (2006).

Assaad F. F., Qiu J. L., Youngs H., Ehrhardt D., Zimmerli L., Kalde M., Wanner G., Peck S. C., Edwards H., Ramonell K., Somerville C. R., Thordal-Christensen H., The PEN1 syntaxin defines a novel cellular compartment upon fungal attack and is required for the timely assembly of papillae. Mol. Biol. Cell. 15, 5118-5129 (2004).

Berbee M. L., James T. Y., Strullu-Derrien C., Early diverging fungi: Diversity and impact at the dawn of terrestrial life. Annu. Rev. Microbiol. 71, 41-60 (2017).

Bhat R. A., Miklis M., Schmelzer E., Schulze-Lefert P., Panstruga R., Recruitment and interaction dynamics of plant penetration resistance components in a plasma membrane microdomain. Proc. Natl. Acad. Sci. 102, 3135-3140 (2005).

Boavida L. C., Qin P., Broz M., Becker J. D., McCormick S., Arabidopsis tetraspanins are confined to discrete expression domains and cell types in reproductive tissues and form homo- and heterodimers when expressed in yeast. Plant Physiol. 163, 696-712 (2013).

Böhlenius H., Mørch S. M., Godfrey D., Nielsen M. E., Thordal-Christensen H., The multivesicular body-localized GTPase ARFA1b/1c is important for callose deposition and ROR2 syntaxindependent preinvasive basal defense in barley. Plant Cell 22, 3831-3844 (2010).

Cai Q., Qiao L., Wang M., He B., Lin F. M., Palmquist J., Huang S. D., Jin H., Plants send small RNAs in extracellular vesicles to fungal pathogen to silence virulence genes. Science. 360, 11261129 (2018).

Carella P., Gogleva A., Tomaselli M., Alfs C., Schornack S., Phytophthora palmivora establishes tissue-specific intracellular infection structures in the earliest divergent land plant lineage. Proc. Natl. Acad. Sci. 115, 3846-3855 (2018). 
469

470

471

472

473

474

475

476

477

478

479

480

481

482

483

484

485

486

487

488

489

490

491

492

493

494

495

496

497

Chang Y., Wang S., Sekimoto S., Aerts A. L., Clum C. C. A., LaButti K. M., Lindquist E. A., Ngan C. Y., Ohm R. A., Salamov A. A., Grigoriev I. V., Spatafora J. W., Berbee M. L., Phylogenomic analyses indicate that early fungi evolved digesting cell walls of algal ancestors of land plants. Genome Biol. Evol. 7, 1590-1601 (2015).

Collett,D. (1991). Modelling Binary Data. (London:Chapman\&Hall).

Collins N. C., Thordal-Christensen H., Lipka V., Bau S., Kombrink E., Qiu J. L., Hückelhoven R., Stein M., Freialdenhoven A., Somerville S. C., Schulze-Lefert P., SNARE-protein-mediated disease resistance at the plant cell wall. Nature. 425, 973-977 (2003).

Ellinger D., Naumann M., Falter C., Zwikowics C., Jamrow T., Manisseri C., Somerville S. C., Voigt C. A. Elevated Early Callose Deposition Results in Complete Penetration Resistance to Powdery Mildew in Arabidopsis. Plant Phys. 161, 1433-44 (2013).

Eschen-Lippold L., Landgraf R., Smolka U., Schulze S., Heilmann M., I Heilmann., Hause G., Rosahl S., Activation of defense against Phytophthora infestans in potato by down-regulation of syntaxin gene expression. New Phytol. 193, 985-996 (2012).

Gao Y., Wang W., Zhang T., Gong Z., Zhao H., Han G. Z., Out of Water: The Origin and Early Diversification of Plant R-Genes. Plant Phys. 177, 82-89 (2018).

Grefen C, Donald N, Hashimoto K, Kudla J, Schumacher K, Blatt MR. A ubiquitin-10 promoterbased vector set for fluorescent protein tagging facilitates temporal stability and native protein distribution in transient and stable expression studies. Plant J. 64, 355-365 (2010).

Hansen L. L., Nielsen M. E., Plant exosomes: using an unconventional exit to prevent pathogen entry? J. Exp. Bot. 69, 59-68 (2018).

Hartmann M, Zeier T, Bernsdorff F, Reichel-Deland V, Kim D, Hohmann M, Scholten N, Schuck S, Bräutigam A, Hölzel T, Ganter C, Zeier J. 2018. Flavin Monooxygenase-Generated NHydroxypipecolic Acid Is a Critical Element of Plant Systemic Immunity. Cell 173:456-469.

Heckman D. S., Geiser D. M., Eidell B. R., Stauffer R. L., Kardos N. L., Hedges S. B., Molecular evidence for the early colonization of land by fungi and plants. Science. 293, 1129-1133 (2001).

Hoefle C., Loehrer M., Schaffrath U., Frank M., Schultheiss H., Hückelhoven R., Transgenic suppression of cell death limits penetration success of the soybean rust fungus Phakopsora pachyrhizi into epidermal cells of barley. Phytopathology. 99, 220-226 (2009). 
498 Horsefield S., Burdett H., Zhang X., Manik M. K., Shi Y., Chen J., Qi T., Gilley J., Lai J. S., Rank 499 M. X., L. Casey W., Gu W., Ericsson D. J., Foley G., Hughes R. O., Bosanac T., von Itzstein M., 500 Rathjen J. P., Nanson J. D., Boden M., Dry I. B., Williams S. J., Staskawicz B. J., Coleman M. P., 501 Ve T., Dodds P. N., Kobe B., NAD ${ }^{+}$cleavage activity by animal and plant TIR domains in cell 502 death pathways. Science 365, 793-799 (2019).

503 Hückelhoven R., Panstruga R., Cell biology of the plant-powdery mildew interaction. Curr. Opin. 504 Plant Biol. 14, 738-746 (2011).

505 Ichikawa M., Hirano T., Enami K., Fuselier T., Kato N., Kwon C., Voigt B., Schulze-Lefert P., 506 Baluška F., Sato M. H., Syntaxin of plant proteins SYP123 and SYP132 mediate root hair tip 507 growth in Arabidopsis thaliana. Plant Cell Physiol. 55, 790-800 (2014).

508 Jarosch B., Collins N. C., Zellerhoff N., Schaffrath U., RAR1, ROR1, and the actin cytoskeleton 509 contribute to basal resistance to Magnaporthe grisea in barley. Mol Plant Microbe Interact. 18, 397$510404(2005)$.

511 Jones J. D. G., Vance R. E., Dangl J. L., Intracellular innate immune surveillance devices in plants 512 and animals. Science. 354 (2016).

513 Kanazawa T., Era A., Minamino N., Shikano Y., Fujimoto M., Uemura T., Nishihama R., Yamato 514 K. T., Ishizaki K., Nishiyama T., Kohchi T., Nakano A., Ueda T., SNARE Molecules in Marchantia 515 polymorpha: Unique and Conserved Features of the Membrane Fusion Machinery. Plant and Cell 516 Physiology. 57, 307-324 (2016).

517 Kanazawa T, Morinaka H, Ebine K, Shimada TL, Ishida S, Minamino N, Yamaguchi K, Shigenobu 518 S, Kohchi T, Nakano A, Ueda T., The liverwort oil body is formed by redirection of the secretory 519 pathway. Nat Commun. 11, 6152 (2020).

520 Karimi M., Inzé D., Depicker A., GATEWAY vectors for Agrobacterium-mediated plant 521 transformation. Trends in Plant Sci. 7, 193-195 (2002).

522 Karnik R., Waghmare S., Zhang B., Larson E., Lefoulon C., Gonzalez W., Blatt M. R., 523 Commandeering Channel Voltage Sensors for Secretion, Cell Turgor, and Volume Control. Trends 524 Plant Sci. 22, 81-95 (2017).

525 Keogh R. C., Deverall B. J., McLeod S., Comparison of histological and physiological responses to 526 Phakopsora pachyrhizi in resistant and susceptible soybean. Trans. Br. Mycol. SOC. 74, 329-333 527 (1980). 
Krings M., Taylor T. N., Hass H., Kerp H., Dotzler N., Hermsen E. J., Fungal endophytes in a 400million-yr-old land plant: infection pathways, spatial distribution, and host responses. New Phytologist. 174, 648-657 (2007).

Kuhn H., Lorek J., Kwaaitaal M., Consonni C., Becker K., Micali C., Ver Loren van Themaat E., Bednarek P., Raaymakers T. M., Appiano M., Bai Y., Meldau D., Baum S., Conrath U., Feussner I., Panstruga R., Key Components of Different Plant Defense Pathways Are Dispensable for Powdery Mildew Resistance of the Arabidopsis mlo2 mlo6 mlo12 Triple Mutant. Front Plant Sci. 8, 1006 (2017).

Kwon C., Panstruga R., Schulze-Lefert P., Les liaisons dangereuses: immunological synapse formation in animals and plants. Trends Immunol. 4, 159-166 (2008).

Latunde-Dada A. O., Bailey J. A., Lucas J. A., Infection process of Colletotrichum destructivum O'Gara from lucerne (Medicago sativa L.). European Journal of Plant Pathology 103, 35-41 (1997).

Lévesque C. A., Fifty years of oomycetes - from consolidation to evolutionary and genomic exploration. Fungal Diversity. 50, 35 (2011).

Lipka V., Dittgen J., Bednarek P., Bhat R., Wiermer M., Stein M., Landtag J., Brandt W., Rosahl S., Scheel D., Llorente F., Molina A., Parker J., Somerville S., Schulze-Lefert P., Pre- and postinvasion defenses both contribute to nonhost resistance in Arabidopsis. Science. 310, 11801183 (2005).

Loehrer M., Langenbach C., Goellner K., Conrath U., Schaffrath U., Characterization of nonhost resistance of Arabidopsis to the Asian soybean rust. Mol. Plant. Microbe. Interact. 21, 1421-1430 (2008).

Karnahl M., Park M., Krause C., Hiller U., Mayer U., Stierhof Y. D., Jürgens G., Functional diversification of Arabidopsis SEC1-related SM proteins in cytokinetic and secretory membrane fusion. Proc.Natl.Acad.Sci. 115, 6309-6314 (2018).

Meyer D., Pajonk S., Micali C., O'Connell R., Schulze-Lefert P., Extracellular transport and integration of plant secretory proteins into pathogen-induced cell wall compartments. Plant J. 57, 986-999 (2009). 
Nielsen M.E., Feechan A., Böhlenius H., Ueda T., Thordal-Christensen H., Arabidopsis ARF-GTP exchange factor, GNOM, mediates transport required for innate immunity and focal accumulation of syntaxin PEN1. Proc.Natl.Acad.Sci. 109, 11443-11448 (2012).

Nielsen M.E., Thordal-Christensen H., Recycling of Arabidopsis plasma membrane PEN1 syntaxin. Plant Signal Behav. 12, 1541-1543 (2012).

Nielsen M. E., Thordal-Christensen H., Transcytosis shuts the door for an unwanted guest. Trends. Plant. Sci. 11, 611-616 (2013).

Nielsen M. E., Jürgens G., Thordal-Christensen H., VPS9a activates the Rab5 GTPase ARA7 to confer distinct pre- and postinvasive plant innate immunity. The Plant Cell. 29, 1927-1937 (2017).

O’Connell R. J., Panstruga R., Tête à tête inside a plant cell: establishing compatibility between plants and biotrophic fungi and oomycetes. New Phytologist. 171, 699-718 (2006).

Overdijk E. J., de Keijzer J., de Groot D., Schoina C., Bouwmeester K., Ketelaar T., Govers F., Interaction between the moss Physcomitrella patens and Phytophthora: a novel pathosystem for live-cell imaging of subcellular defence. J. Microsc. 263, 171-180 (2016).

Park M., Krause C., Karnahl M., Reichardt I., El Kasmi F., Mayer U., Stierhof Y. D., Hiller U., Strompen G., Bayer M., Kientz M., Sato M. H., Nishimura M. T., Dangl J. L., Sanderfoot A. A., Jürgens G. Concerted Action of Evolutionarily Ancient and Novel SNARE Complexes in Flowering-Plant Cytokinesis. Developmental Cell. 44, 500-511 (2018).

Pajonk S., Kwon C., Clemens N., Panstruga R., Schulze-Lefert P., Activity Determinants and Functional Specialization of Arabidopsis PEN1 Syntaxin in Innate Immunity. J. Biol. Chem. 283, 26974-26984 (2008).

Pirozynski K. A., Malloch D. W., The origin of land plants: a matter of mycotropism. Biosystems. 6, 153-164 (1975).

Redecker D., Kodner R., Graham L. E., Glomalean fungi from the Ordovician. Science. 289, 1920$1921(2000)$.

Rodriguez-Furlán C, Salinas-Grenet H, Sandoval O, Recabarren C, Arraño-Salinas P, Soto-Alvear S, Orellana A, Blanco-Herrera F. 2016. The Root Hair Specific SYP123 Regulates the Localization of Cell Wall Components and Contributes to Rizhobacterial Priming of Induced Systemic Resistance. Front Plant Sci. 7, 1081 (2016). 
Rutter B. D., Innes R. W., Extracellular Vesicles Isolated from the Leaf Apoplast Carry StressResponse Proteins. Plant Physiol. 173, 728-741 (2017).

Sanderfoot A., Increases in the number of SNARE genes parallels the rise of multicellularity among the green plants. Plant Physiol. 144, 6-17 (2007).

Schultz-Larsen T., Lenk A., Kalinowska K., Vestergaard L. K., Pedersen C., Isono E., ThordalChristensen H., The AMSH3 ESCRT-III-associated deubiquitinase is essential for plant immunity. Cell Rep. 25, 2329-2338 (2018).

Shimada C., Lipka V., O'Connell R., Okuno T., Schulze-Lefert P., Takano Y., Nonhost Resistance in Arabidopsis-Colletotrichum Interactions Acts at the Cell Periphery and Requires Actin Filament Function. Mol. Plant. Microbe. Interact. 19, 270-279 (2006).

Slane D., Reichardt I., El Kasmi F., Bayer M., Jürgens G., Evolutionarily diverse SYP1 QaSNAREs jointly sustain pollen tube growth in Arabidopsis. Plant J. 92, 375-385 (2017).

Stein M, Dittgen J, Sánchez-Rodríguez C, Hou BH, Molina A, Schulze-Lefert P, Lipka V, Somerville S. Arabidopsis PEN3/PDR8, an ATP binding cassette transporter, contributes to nonhost resistance to inappropriate pathogens that enter by direct penetration. Plant Cell 3, 731-746 (2006).

Takikawa Y., Senga Y., Nonomura T., Matsuda Y., Kakutani K., Toyoda T., Targeted destruction of fungal structures of Erysiphe trifoliorum on flat leaf surfaces of Marchantia polymorpha. Plant Biol. 16, 291-295 (2013).

Thordal-Christensen H, Zhang Z, Wei Y, Collinge D.B. 1997. Subcellular localization of H2O2 in plants. $\mathrm{H} 2 \mathrm{O} 2$ accumulation in papillae and hypersensitive response during the barley-powdery mildew interaction. Plant Jour. 11:1187-1194.

Tzelepis G., Hodén K. P., Fogelqvist J., Åsman A. K. M., Vetukuri R. R., Dixelius C., Dominance of Mating Type A1 and Indication of Epigenetic Effects During Early Stages of Mating in Phytophthora infestans. Front Microbiol. 11, 252 (2020).

Waghmare S., Lileikyte E., Karnik R., Goodman J. K., Blatt M. R., Jones A. M. E., Arabidopsis SNAREs SYP121 and SYP122 mediate the secretion of distinct cargo subsets. Plant Physiol. 178, 1679-1688 (2018).

Wan L., Essuman K., Anderson R. G., Sasaki Y., Monteiro F., Chung E. H., Osborne E., Nishimura, DiAntonio A., Milbrandt J., Dangl J. L., Nishimura M. T., TIR domains of plant 
immune receptors are NAD+-cleaving enzymes that promote cell death. Science 365, 799-803 (2019).

Wang J., Wang J., Hu M., Wu S., Qi J., Wang G., Han Z., Qi Y., Gao N., Wang H. W., Zhou J. M., Chai J., Ligand-triggered allosteric ADP release primes a plant NLR complex. Science 364, eaav5868 (2019a).

Wang J., Hu M., Wang J., Qi J., Han Z., Wang G., Qi Y., Wang H. W., Zhou J. M., Chai J., Reconstitution and structure of a plant NLR resistosome conferring immunity. Science. 364, eaav5870 (2019b).

Wen Y., Wang W., Feng J., Luo M. C., Tsuda K., Katagiri F., Bauchan G., Xiao S., Identification and utilization of a sow thistle powdery mildew as a poorly adapted pathogen to dissect postinvasion non-host resistance mechanisms in Arabidopsis. J. Exp.Bot. 62, 2117-2129 (2011).

Yang L., Qin L., Liu G., Peremyslov V. V., Dolja V. V., Wei Y., Myosins XI modulate host cellular responses and penetration resistance to fungal pathogens. Proc. Natl. Acad. Sci. U S A. 23, 1399614001 (2014).

Zeyen RJ, Carver TLW, Lyngkjær MF. 2002. Epidermal cell papillae. In: Bélanger RR, Bushnell WR, Dik AJ, Carver TLW, eds. The powdery mildews. A comprehensive treatise. St Paul, MN: APS Press, 107-125.

Zhang Z., Feechan A., Pedersen C., Newman M. A., Qiu J. L., Olesen K. L., Thordal-Christensen H., A SNARE-protein has opposing functions in penetration resistance and defence signalling pathways. Plant J. 49, 302-312 (2007).

Zhang Z., Lenk A., Andersson M. X., Gjetting T., Pedersen C., Nielsen M. E., Newman M. A., Hou B. H., Somerville S. C., Thordal-Christensen H., A lesion-mimic syntaxin double mutant in Arabidopsis reveals novel complexity of pathogen defense signaling. Mol. Plant. 1, 510-527 (2008).

\section{Acknowledgments}

We would like to thank Takashi Ueda for providing Marchantia polymorpha lines and cDNA clones of MpSYPs (Kanazawa et al., 2016). Also to Bent Jørgen Nielsen and Christina Dixelius for providing Phytophthora infestans. We are grateful to Christine Strullu-Derrien for fruitful discussions on the evolution of plant-fungus interactions and to Hans Thordal-Christensen, Stefan 
643 Wenkel, Sebastian Marquardt, Morten Petersen and Pierre-Marc Delaux for useful comments on the 644 manuscript. Funding: This project was supported by grants from the Villum Foundation (M.E.N, 645 VKR023502), Independent Research Fund Denmark, Technical and Production Sciences (M.E.N., 646 6111-00524B), Novo Nordisk Foundation (M.E.N., NNF19OC0056457), Agence Nationale de la 647 Recherche (R.J.O., ANR-17-CAPS-0004-01) and China Scholarship Council (M.L., No. 648 201906300075). Competing interests: The authors declare no competing interests. Materials 649 availability: All materials are available on request.

650

651 Materials and Methods

\section{Key Resources Table}

\begin{tabular}{|c|c|c|c|c|}
\hline $\begin{array}{l}\text { Reagent type } \\
\text { (species) or } \\
\text { resource }\end{array}$ & Designation & $\begin{array}{l}\text { Source or } \\
\text { reference }\end{array}$ & Identifiers & $\begin{array}{l}\text { Additional } \\
\text { information }\end{array}$ \\
\hline $\begin{array}{l}\text { gene } \\
\text { (Arabidopsis } \\
\text { thaliana) }\end{array}$ & $\begin{array}{l}\text { pen1-1 } \\
\text { syp122-1 }\end{array}$ & $\begin{array}{l}\text { Assaad et al., } \\
2004\end{array}$ & & $\begin{array}{l}\text { See } \\
\text { Materials } \\
\text { and methods }\end{array}$ \\
\hline $\begin{array}{l}\text { gene } \\
\text { (Arabidopsis } \\
\text { thaliana) }\end{array}$ & $\begin{array}{l}\text { fmo 1-1 } \\
\text { pen1-1 } \\
\text { syp 122-1 }\end{array}$ & $\begin{array}{l}\text { Zhang et al., } \\
2008\end{array}$ & & $\begin{array}{l}\text { See } \\
\text { Materials } \\
\text { and methods }\end{array}$ \\
\hline $\begin{array}{l}\text { gene } \\
\text { (Arabidopsis } \\
\text { thaliana) }\end{array}$ & $\begin{array}{l}\text { amsh3-4 } \\
\text { pen1-1 } \\
\text { syp 122-1 }\end{array}$ & $\begin{array}{l}\text { Schultz-Larsen } \\
\text { et al., } 2018\end{array}$ & & $\begin{array}{l}\text { See } \\
\text { Materials } \\
\text { and methods }\end{array}$ \\
\hline $\begin{array}{l}\text { gene } \\
\text { (Arabidopsis } \\
\text { thaliana) }\end{array}$ & $\begin{array}{l}\text { sid2 pad4 } \\
\text { pen1 syp122 }\end{array}$ & $\begin{array}{l}\text { Zhang et al., } \\
2004\end{array}$ & & $\begin{array}{l}\text { See } \\
\text { Materials } \\
\text { and methods }\end{array}$ \\
\hline $\begin{array}{l}\text { gene } \\
\text { (Arabidopsis } \\
\text { thaliana) }\end{array}$ & TET8-GFP & $\begin{array}{l}\text { Boavida et al., } \\
2013\end{array}$ & & $\begin{array}{l}\text { See } \\
\text { Materials } \\
\text { and methods }\end{array}$ \\
\hline
\end{tabular}


654

655

656

657

658

659

660

661

662

663

664

665

666

667

668

669

670

671

672

673

674

675

676

677

678

679

680

681

682

683

684

Plants of Arabidopsis thaliana and Marchantia polymorpha (Tak-1) were grown at $21^{\circ} \mathrm{C}$, with $8 \mathrm{~h}$ of light at 125 micro Einstein $\mathrm{s}^{-1} \mathrm{~m}^{-2}$ per day. All mutant plant lines were reported previously (Collins et al., 2003; Assaad et al., 2004; Zhang et al., 2008; Rodriguez-Furlan et al., 2016; SchultzLarsen et al., 2018). The barley powdery mildew fungus, Bgh (B. graminis f.sp. hordei, isolate C15) and Arabidopsis powdery mildew, G. orontii, were propagated on barley and Arabidopsis, respectively. C. destructivum isolate LARS 709 and C. higginsianum isolate IMI 349063A was cultured on Mathur's medium containing glucose (2.8 g), $\mathrm{MgSO}_{4}-7 \mathrm{H}_{2} \mathrm{O}(1.22 \mathrm{~g}), \mathrm{KH}_{2} \mathrm{PO}_{4}(2.72 \mathrm{~g})$, Oxoid Mycological peptone (2.18 g) and agar (30 g) in 1 liter of deionised water at $25^{\circ} \mathrm{C}$ in the dark. The P. infestans (field isolate 2017-DK-31-03 and SW1_A1) was cultured on rye sucrose (2\%) agar supplemented with $\beta$-sitosterol (50mg/L), Pimaricin (10mg/L) and Ampicillin (100mg/L) at $18^{\circ} \mathrm{C}$ in the dark (Tzelepis et al., 2020).

\section{$\underline{\text { Infection studies }}$}

Spores from Bgh and G.orontii were blown evenly onto the leaves of 4-week-old Arabidopsis plants and kept at $21^{\circ} \mathrm{C}$. For Colletotrichum, spores were harvested in water from a 7-10 day old culture. Spores were adjusted to a final concentration of $5 \times 10^{5}$ or $1 \times 10^{6}$ spores $\mathrm{ml}^{-1}$ and sprayed evenly onto the leaves of 5-week-old Arabidopsis plants. Following inoculation, the plants were sealed inside plastic bags and kept at $21^{\circ} \mathrm{C}$. Zoospores of $P$. infestans were released from sporangia by addition of cold water and incubation at $4{ }^{\circ} \mathrm{C}$ for $90 \mathrm{~min}$. The zoospore suspension was diluted to 5 $\mathrm{x} 10^{5}$ or $1 \times 10^{6}$ spores/ml and added to the abaxial side of attached leaves from 4-week-old Arabidopsis plants. The leaves were kept in a closed Petri dish on water-soaked filter paper at $21^{\circ} \mathrm{C}$.

For scoring penetration success, leaf material was Trypan blue-stained at $24 \mathrm{~h}$ post inoculation for $B g h$ or $P$. infestans, $48 \mathrm{~h}$ post inoculation for $G$. orontii and $72 \mathrm{~h}$ post inoculation for $C$. destructivum (Keogh et al., 1980). Penetration was determined by the presence of a developing IPS inside epidermal cells using light microscopy. To avoid the possibility that cells undergoing programmed cell death would be restricted in their encasement response to IPS, these cells were excluded from our observations based on Trypan blue staining. Once the penetration status for a particular event was determined, only then was the callose response investigated. For staining of live fungal structures, infected leaves were vacuum infiltrated with propidium iodide $(10 \mu \mathrm{M})$ for 2 hours. Callose staining was performed using $0.01 \%$ Aniline blue in $1 \mathrm{M}$ glycine [adjusted to $\mathrm{pH} 9.5$ using $\mathrm{NaOH}$ ] and visualized by UV epifluorescence. All experiments were repeated at least three 
685

686

687

688

689

690

691

692

693

694

695

696

697

698

699

700

701

702

703

704

705

706

707

708

709

710

711

times with similar results. Data from the individual studies described above represent discrete variables since it was recorded whether or not a certain event had taken place (e.g., whether or not a spore caused penetration). Consequently, these data were analysed by logistic regression, assuming a binomial distribution (corrected for over-dispersion when present) (Collet, 1991). Hypotheses were rejected at $\mathrm{P}<0.001$. All data were analysed by PC-SAS (release 9.4; SAS Institute, Cary, NC).

\section{$\underline{\text { RNA isolation and quantitative PCR }}$}

Total RNA was isolated from A. thaliana tissue using Monarch® Total RNA Miniprep Kit (NEB). cDNA was synthesized using ProtoScript ${ }^{\circledR}$ II First Strand cDNA Synthesis Kit (NEB) and an oligo(dT) primer. Transcript quantification was performed using the 5x HOT FIREPol EvaGreen qPCR Mix Plus (SOLIS BIODYNE) on a Stratagene MX3000P real-time PCR detection system. Gene specific primers are described below. We used the At4g26410 transcript as internal control.

\section{REF1_F2 TGAAGCTGCTGATTTGATGGA}

REF1_R2 CTCTAAGCTTGATAGCATCCCTTC

PR1-F2 GAACACGTGCAATGGAGTTTG

PR1-R2 CACTTTGGCACATCCGAGTCT

\section{$\underline{\text { Constructs }}$}

Open reading frames (ORFs) of PEN1 and SYP122 were amplified by PCR from cDNA and the amplified products were subcloned into pDONR221 (Invitrogen). Along with pENTR clones containing MpSYP12A and MpSYP12B (Kanazawa et al., 2016), PEN1 and SYP122 were cloned into pUBIN-GFP, and PEN1 also in pB7WGR2, (Karimi et al., 2002; Grefen et al., 2010) destination vectors according to the manufacturer's instructions. For cloning, the following primers were used:

attB1-for GGGGACAAGTTTGTACAAAAAAGCAGGCTAC

attB2-rev GGGGACCACTTTGTACAAGAAAGCTGGGTC

\section{B1-PEN1-for}

AAAAAGCAGGCTACATGAACGATTTGTTTTCC 
B2-PEN1-rev

B1-SYP122-for

B2-SYP122-rev
AGAAAGCTGGGTCTCAACGCAATAGACGCCTTGC

AAAAAGCAGGCTACATGAACGATCTTCTCTCC

AGAAAGCTGGGTCTTAGCGTAGTAGCCGCCG

\section{Fluorescent protein, propidium iodide and callose detection using confocal microscopy}

Samples were examined using a $63 \times$ water immersion lens mounted on a Leica CLSM TCS SP5 confocal microscope. For detection and localization of the fluorophores and stains, GFP and propidium iodide were excited at $488 \mathrm{~nm}$ and detected between 500 - and $520 \mathrm{~nm}$, and 555- and 615 $\mathrm{nm}$, respectively. Aniline blue-stained callose was excited at $405 \mathrm{~nm}$ and detected between 435 - and $485 \mathrm{~nm}$. Imaging data were collected at the Center for Advanced Bioimaging (CAB) Denmark, University of Copenhagen. Projections of serial confocal sections, image overlays, and contrast enhancement were performed using image processing software (GIMP 2).

\section{Figure legends:}

Figure 1. PEN1/SYP122 are required for papilla and encasement responses to $\boldsymbol{B g h}$. (A, B) Spontaneous callose depositions in leaves of 3 week old plants. (C-G) Accumulation of callose in response to $B g h$ attack at appressoria (arrows) and primary germ tube (arrowheads) in (C-D) nonpenetrated cells and (E-G) and cells following a successful penetration. Open arrows point to the developing IPS. (G) Same as F, but optical section taken below the point of entry. * marks cells with cell death response. Bars $=20 \mu \mathrm{m}$.

Figure 1-figure supplement 1. Pre- and post-invasive immunity. (A) Attack by non-adapted filamentous pathogens such as Bgh on Arabidopsis, is met by a localized apposition (papilla) formed between the plant cell wall (CW) and the plasma membrane (PM), containing callose, phenolic compounds, reactive oxygen species, and exosomes, that likely prevents penetration (Zeyen et al., 2002; Assaad et al., 2004; An et al., 2006). (B) Upon successful penetration, the host cell forms an encasement, similar in composition to the papilla, that eventually encloses the developing haustorium $(\mathrm{H})$ and prevents nutrient uptake. Similar to $B g h$, spores of $C$. destructivum 
and $P$. infestans attempt to penetrate and form an intracellular pathogenic structure (IPS, haustoria, biotrophic hypae and infection vesicle, respectively). In the case of an ineffective encasement response, the host cell initiates a cell death response that prevents pathogen growth. (C-D) Accumulation of callose in response to successful penetration by $G$. orontii $(24 \mathrm{~h})$. Open arrows point to the developing IPS. Bars $=20 \mu \mathrm{m}$.

Figure 1 - Video 1. Z-stack (callose and bright field overlay) of successful penetration by $B g h$ in Col-0.

Figure 1 - Video 2. Z-stack (callose and bright field overlay) of successful penetration by Bgh in pen1 syp122.

Figure 1 - Video 3. Z-stack (callose and bright field overlay) of successful penetration by $G$. orontii in Col-0.

Figure 1 - Video 4. Z-stack (callose and bright field overlay) of successful penetration by $G$. orontii in pen1 syp122.

Figure 2. PEN1/SYP122 are required for accumulation of TET8-GFP in response to penetration by Bgh. (A-D) Localization of TET8-GFP in (A, C) resting epidermal cells and in (B, D) response to successful penetration by Bgh (stained with propidium iodide, PI) and initiation of the IPS (arrows). Bars $=10 \mu \mathrm{m}$.

Figure 2 - Video 1. Z-stack (GFP and propidium iodide overlay) of successful penetration by $B g h$ in Col-0.

Figure 2 - Video 2. Z-stack (GFP and propidium iodide overlay) of successful penetration by $B g h$ in pen1 syp122.

\section{Figure 3: PEN1/SYP122 are required for papilla responses towards Bgh. (A-B, D-E)} Accumulation of callose (A-B) or $\mathrm{H}_{2} \mathrm{O}_{2}$ (D-E) in response to $\mathrm{Bgh}$ attack (arrows) at non-penetrated attack sites. Bars $=10 \mu \mathrm{m}$. (C, F) Frequency of papillae in response to $B g h$ in non-penetrated cells as detected by staining for callose $(\mathrm{C})$ or $\mathrm{H}_{2} \mathrm{O}_{2}(\mathrm{~F})$. (C, F) All values are mean $\pm \mathrm{SD}(\mathrm{n}=5$ leaves per genotype). Different letters indicate significantly different values at $\mathrm{P} \leq 0.001$ estimated using logistic regression. 
Figure 3-figure supplement 1. Loss of FMO1 attenuates pen1 syp122 autoimmunity. (A) Plants at 4 weeks, showing the growth phenotypes of the mutant lines used in these studies. (B) Relative transcript levels of PR1 in four week old plants. (F) Values are mean $\pm \mathrm{SD}(\mathrm{n}=3)$. ***, $P<0.001$, Student's t test. (C-D) Accumulation of callose in response to $G$ orontii- (48 h). Open- arrows and arrow heads point to the developing IPS and secondary hyphae, respectively. Bars $=20 \mu \mathrm{m}$.

Figure 3-figure supplement 2. PEN1/SYP122 are required for papilla responses to $B g h$. (A-D) Accumulation of callose in response to Bgh attack at non-penetrated (arrowheads) and penetrated (arrows) attack sites. Bars $=20 \mu \mathrm{m}$.

Figure 4: PEN1/SYP122 are required for encasement responses towards $\boldsymbol{B g h}$. (A-B, D) Accumulation of callose (A-B) or $\mathrm{H}_{2} \mathrm{O}_{2}$ (D) in response to $B g h$ attack (arrows) at penetrated attack sites. Open arrows point to the developing IPS. Bars $=10 \mu \mathrm{m} .(\mathrm{C}, \mathrm{E})$ Frequency of encasements in response to $\mathrm{Bgh}$ in penetrated cells as detected by staining for callose (C) or $\mathrm{H}_{2} \mathrm{O}_{2}$ (E). (F) Frequency of penetrations by $B g h$. (C, E-F) All values are mean \pm SD ( $n=5$ leaves per genotype). Different letters indicate significantly different values at $\mathrm{P} \leq 0.001$ estimated using logistic regression.

Figure 4-figure supplement 1. PEN1/SYP122 are required for encasement responses to $B g h$. (A-D) Accumulation of callose in response to $B g h$ attack at non-penetrated (arrowheads) and penetrated (arrows) attack sites. Open arrows point to the developing IPS. * marks cells with cell death response. Bars $=20 \mu \mathrm{m}$.

Figure 4-figure supplement 2. PEN1/SYP122 are required for papilla and encasement responses to Bgh. (A-F) Accumulation of callose in response to (A-B) G. orontii- and (C-F) Bgh (48 hours) attack at (C-D) non-penetrated and (A-B, E-F) penetrated attack sites (arrows). Open arrows point to the developing IPS. Open- arrows and arrow heads point to the developing IPS and secondary hyphae, respectively. Bars $=20 \mu \mathrm{m}$.

Figure 4 - Video 1. Z-stack (callose and bright field overlay) of successful penetration by $G$. orontii in fmol.

Figure 4 - Video 2. Z-stack (callose and bright field overlay) of successful penetration by $G$. orontii in fmol pen1 syp122.

Figure 4 - Video 3. Z-stack (callose and bright field overlay) of successful penetration by $G$. orontii in pad4 sid2 pen1 syp122. 
798

799

800

801

802

803

804

805

806

807

808

809

810

811

812

813

814

815

816

817

818

819

820

821

822

823

824

825

826

827

Figure 4 - Video 4. Z-stack (callose and bright field overlay) of successful penetration by $G$. orontii in amsh3 pen1 syp122.

Figure 4 - Video 5. Z-stack (callose and bright field overlay) of successful penetration by Bgh in fmol.

Figure 4 - Video 6. Z-stack (callose and bright field overlay) of successful penetration by Bgh in fmol pen1 syp122.

Figure 4 - Video 7. Z-stack (callose and bright field overlay) of successful penetration by Bgh in pad4 sid2 pen1 syp122.

Figure 4 - Video 8. Z-stack (callose and bright field overlay) of successful penetration by Bgh in amsh3 pen1 syp122.

Figure 5: PEN1/SYP122 are required for pre-invasive immunity towards $C$. destructivum. (A,B and D,E) Accumulation of callose in response to attack by melanized C. destructivum appressoria (arrows) at (A and B) non-penetrated and (D and E) penetrated attack sites. Open arrows point to the developing IPS. Bars $=10 \mu \mathrm{m}$. (C) Frequency of papillae in response to $C$. destructivum in non-penetrated cells. (F) Frequency of penetrations by $C$. destructivum. (C, F) All values are mean \pm SD ( $n=4$ leaves per genotype). Different letters indicate significantly different values at $\mathrm{P} \leq 0.001$ estimated using logistic regression.

Figure 5-figure supplement 1. PEN1/SYP122 are required for pre-invasive immunity towards C. destructivum. (A-C) Localisation of GFP-PEN1 (A), GFP-SYP122 (B) and TET8-GFP (C) in response to attack by $C$. destructivum. (D-E) Accumulation of callose in response to attack by $C$. destructivum in (D) non-penetrated cells and (E) at penetration sites (arrows). Open arrows point to the developing IPS. * marks cell with cell death response. (F) Frequency of penetration by $C$. destructivum. (G) Macroscopic phenotype at 5 dai with $C$. destructivum. Bars $=10 \mu \mathrm{m}$. (F) All values are mean \pm SD ( $n=4$ leaves per genotype). Different letters indicate significantly different values at $\mathrm{P} \leq 0.001$ estimated using logistic regression.

Figure 6: PEN1/SYP122 are required for pre-invasive immunity towards $P$. infestans. (A-B, D-E) Accumulation of callose in response to P. infestans attack (arrows) at (A and B) nonpenetrated and $(\mathrm{D}$ and $\mathrm{E})$ penetrated attack sites. Open arrows point to the developing IPS. Bars = $10 \mu \mathrm{m}$. (C) Frequency of papillae in response to P. infestans in non-penetrated cells. (F) Frequency of penetrations by $P$. infestans. (C, F) All values are mean \pm SD ( $n=4$ leaves per genotype). 
Different letters indicate significantly different values at $\mathrm{P} \leq 0.001$ estimated using logistic regression.

Figure 6-figure supplement 1. PEN1/SYP122 are required for pre-invasive immunity towards P. infestans. (A-C) Localisation of GFP-PEN1 (A), GFP-SYP122 (B) and TET8-GFP (C) in response to attack by $P$. infestans. (D) Frequency of penetration by P.infestans. Bars $=10 \mu \mathrm{m}$. (D) All values are mean $\pm \mathrm{SD}$ ( $\mathrm{n}=4$ leaves per genotype). Different letters indicate significantly different values at $\mathrm{P} \leq 0.001$ estimated using logistic regression.

Figure 7. Responses in Marchantia polymorpha to filamentous pathogens. (A-B) Accumulation of callose in Marchantia in response to attack (arrows) by (A) P. infestans or (B) C. destructivum in non-penetrated cells. Note that the frequency of $P$. infestans spores that attack a host-cell is very low. (C-F) mCitrine signal of MpSYPs in response to attack (arrows) by $C$. destructivum in nonpenetrated cells. We did not observe any successful penetrations in Marchantia by C. destructivum. Bars $=10 \mu \mathrm{m}$.

Figure 7-figure supplement 1. Responses in Marchantia polymorpha to filamentous pathogens. (A) On M. polymorpha, spores from Bgh (dotted line) were mis-differentiated with no or wrongly orientated appressoria that did not attack the host-cell. (B) Accumulation of callose in $M$. polymorpha in response to attack by $P$. infestans (arrows) in penetrated cells. Open arrow points to the developing IPS. Note that the frequency of $P$. infestans spores that attack a host-cell is very low. Bars $=10 \mu \mathrm{m}$.

Figure 8: Marchantia syntaxins rescue papilla and encasement responses in Arabidopsis. (A, B) Accumulation of callose in response to attack (arrow) by Bgh in (A) non-penetrated- and (B) penetrated cells. Open arrow points to the developing IPS. (C, D) Localization of MpSYP12A and PEN1 in response to attack (arrows) by $B g h$ in (C) non-penetrated- and (D) penetrated cells. Bars = $10 \mu \mathrm{m}$. (E ,F) Frequency of penetration by (E) Bgh and (F) P. infestans. All values are mean \pm SD (n $=4$ leaves per genotype). Different letters indicate significantly different values at $\mathrm{P} \leq 0.001$ estimated using logistic regression.

Figure 8-figure supplement 1. Marchantia syntaxins are functional in Arabidopsis. (A) Plants at five weeks, expressing SYP12 clade members from either Arabidopsis or Marchantia polymorpha. (B) Localization of Marchantia SYP12 clade members in the epidermis of leaves from plants of four weeks. Bars $=10 \mu \mathrm{m}$. 

Accumulation of callose in response to Bgh attack at non-penetrated (arrows) attack sites. Bars $=10$ $\mu \mathrm{m}$. (B) Frequency of papillae in response to $B g h$ in non-penetrated cells. All values are mean $\pm S D$ $(\mathrm{n}=5$ leaves per genotype). Different letters indicate significantly different values at $\mathrm{P} \leq 0.001$ estimated using logistic regression.

Figure 8-figure supplement 3. Marchantia syntaxins rescue encasement responses. (A) Accumulation of callose in response to $B g h$ attack at successful penetration sites. Open arrows point to the developing IPS. Bars $=10 \mu \mathrm{m}$. (B) Frequency of encasements in response to $B g h$ haustoria in penetrated cells. All values are mean $\pm \mathrm{SD}(\mathrm{n}=5$ leaves per genotype). Different letters indicate significantly different values at $\mathrm{P} \leq 0.001$ estimated using logistic regression.

Figure 8-figure supplement 4. Localization of SYP12 clade members at $B g h$ attack sites. Comparative papilla localization of SYP12 members from Arabidopsis or Marchantia in response to attack by $B g h$ in non-penetrated cells. Bars $=10 \mu \mathrm{m}$.

Figure 8-figure supplement 5. Localization of SYP12 clade members at $B g h$ penetration sites. Comparative encasement localization of SYP12 members from Arabidopsis or Marchantia in response to haustoria by $B g h$ in penetrated cells. Bars $=10 \mu \mathrm{m}$.

Figure 8-figure supplement 6. Marchantia SYP12s restore immunity in Arabidopsis towards $C$. destructivum. (A) Macroscopic phenotype at 5 dai with $C$. destructivum. (B-D) Frequency of penetration by $C$. destructivum (B), G. orontii (C) and C. higginsianum (D). (B-D) All values are mean $\pm \mathrm{SD}(\mathrm{n}=4$ leaves per genotype). Different letters indicate significantly different values at $\mathrm{P} \leq$ 0.001 estimated using logistic regression.

Figure 8-figure supplement 7. Localization of Marchantia SYP12 clade members at attack sites. (A-D) Localization of GFP-MpSYP12A (A, C) and GFP-MpSYP12A (B, D) in response to attack by $P$. infestans (A-B) and C. destructivum (C-D) in non-penetrated cells. Bars $=10 \mu \mathrm{m}$.

Fig. 9. Simplified model of syntaxin mediated immunity. In response to attack by filamentous pathogens, cargo for the papilla/encasement is received at the plasma membrane (PM) by PEN1 or SYP122 and secreted in between the plant cell wall $(\mathrm{CW})$ and the PM . For pre-invasive immunity against powdery mildew fungi, PEN1 is required at the TGN to enable recycling of cargo that facilitates a fast papilla response (shown in red). The general papilla/encasement response (shown in green) does not require PEN1. Instead, this response likely involves a specialization of the 
888 conventional secretory pathway or an alternative recycling pathway that is not dependent on PEN1.

889 Likely, the fast papilla response pathway also contributes to formation of the encasement resulting 890 in a mixture of cargo (such as exosomes and antimicrobial metabolites) transported by the two 891 pathways.

892

893 Source files:

894 Figure 3 Source Data File: Source data for the graphs in figure 3C and F. 895 Figure 4 Source Data File: Source data for the graphs in figure 4C, E and F.

896 Figure 5 Source Data File: Source data for the graphs in figure 5C and F.

897 Figure 6 Source Data File: Source data for the graphs in figure 6C and F.

898 Figure 8 Source Data File: Source data for the graphs in figure 8E and F.

899

900 


\section{Figure 1}
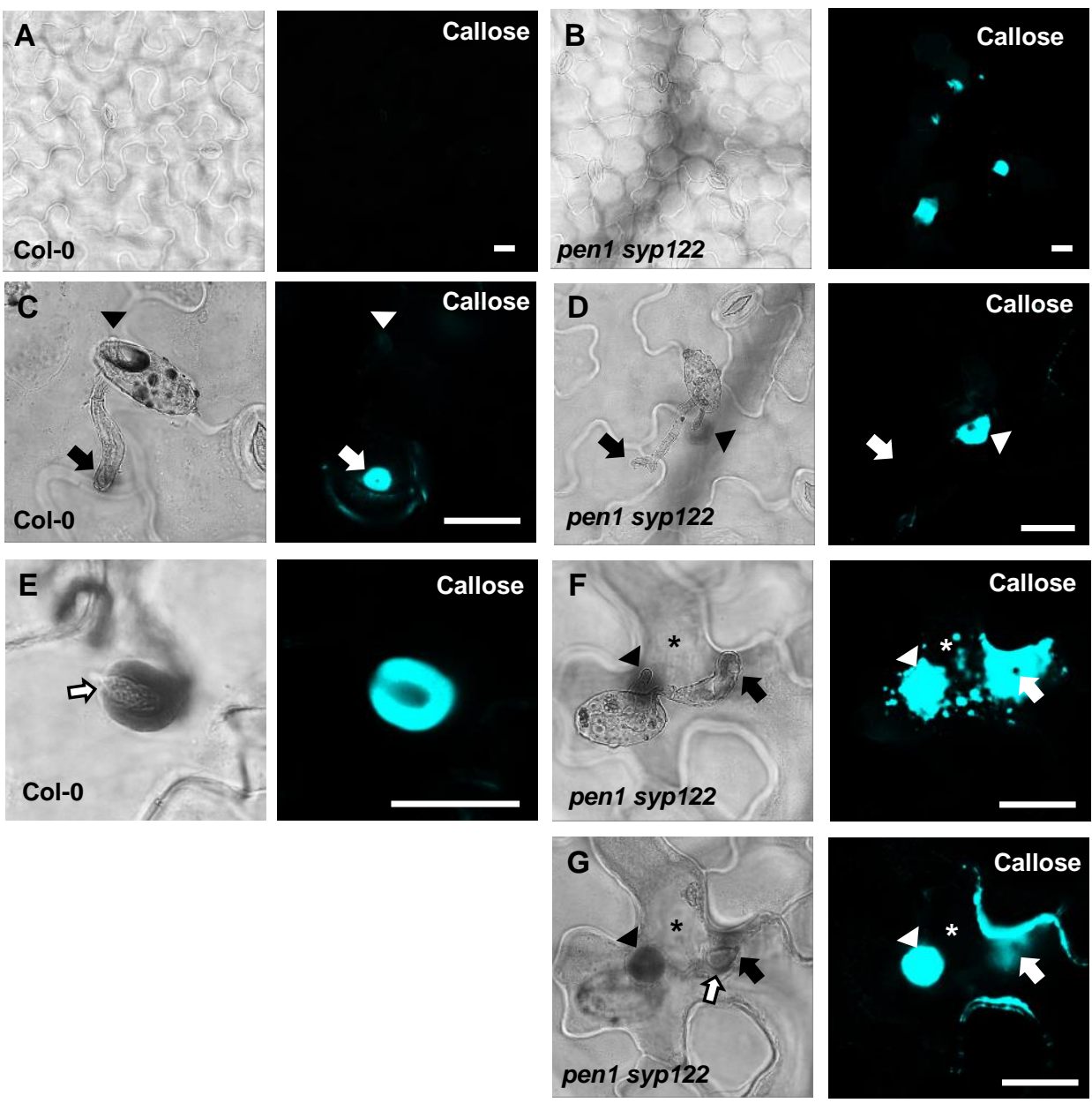

Figure 1. PEN1/SYP122 are required for papilla and encasement responses to Bgh. (A, B) Spontaneous callose depositions in leaves of 3 week old plants. (C-G) Accumulation of callose in response to Bgh attack at appressoria (arrows) and primary germ tube (arrowheads) in (C-D) non-penetrated cells and (E-G) and cells following a successful penetration. Open arrows point to the developing IPS. (G) Same as F, but optical section taken below the point of entry. * marks cells with cell death response. Bars $=20 \mu \mathrm{m}$. 


\section{Figure 2}
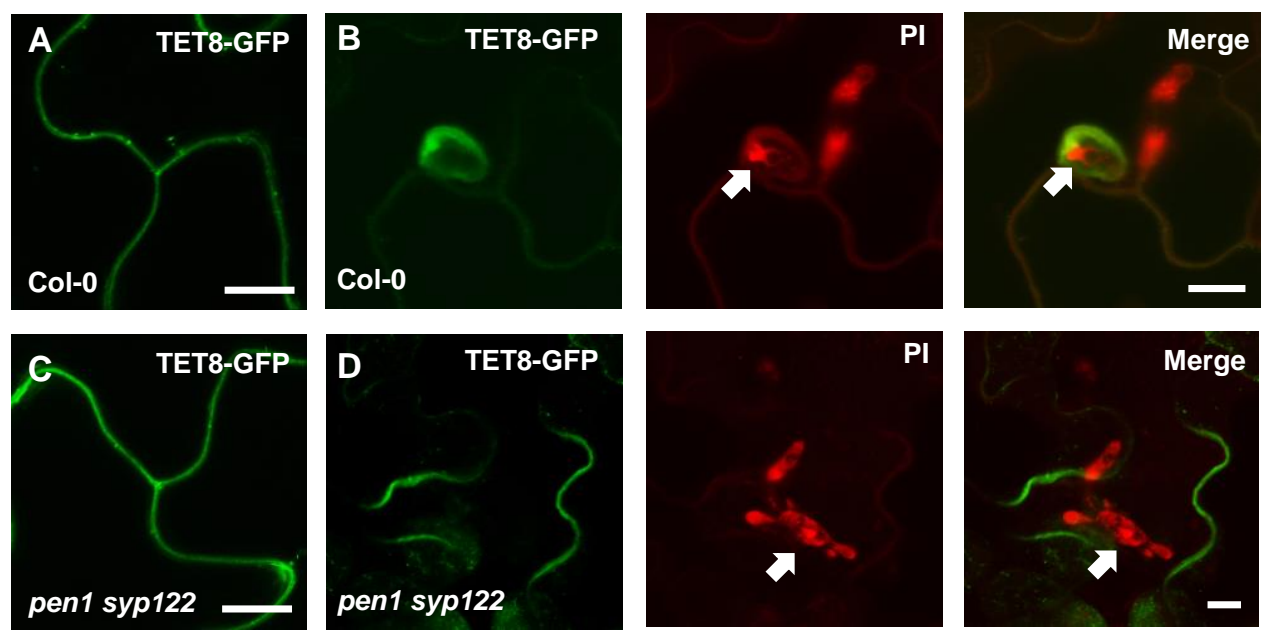

Figure 2. PEN1/SYP122 are required for accumulation of TET8-GFP in response to penetration by Bgh. (A-D) Localization of TET8-GFP in (A, C) resting epidermal cells and in $(B, D)$ response to successful penetration by $B g h$ (stained with propidium iodide, $\mathrm{Pl}$ ) and initiation of the IPS (arrows). Bars $=10 \mu \mathrm{m}$. 


\section{Figure 3}
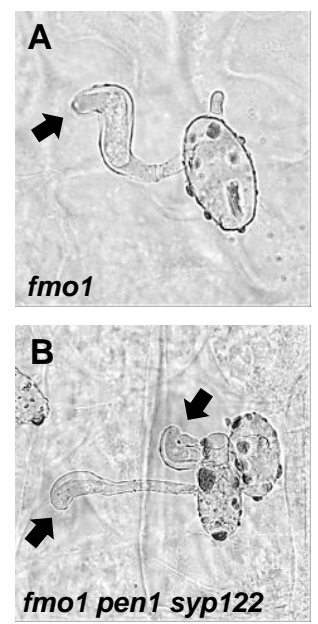

C

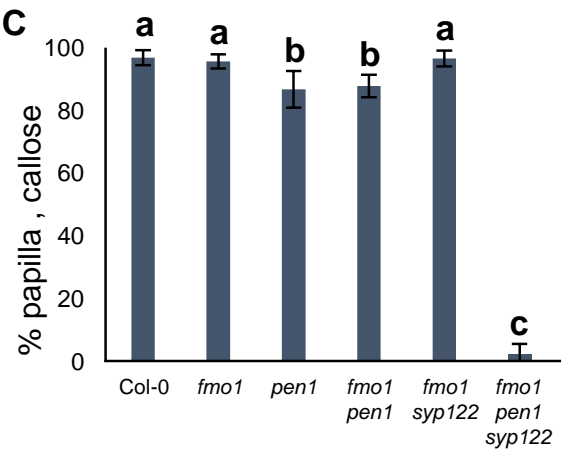

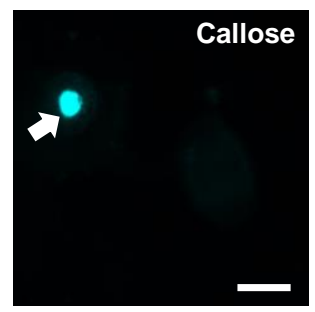

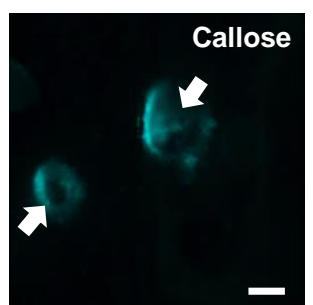

fmo1
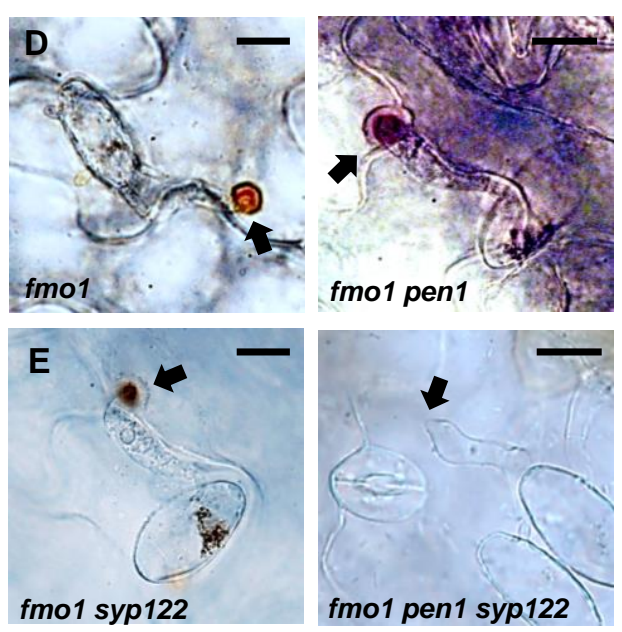

F

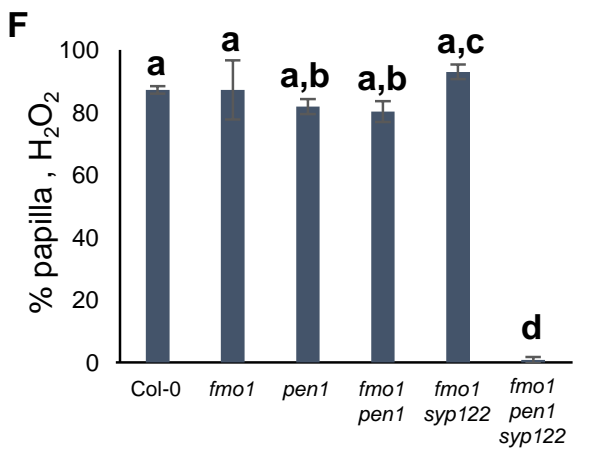

Figure 3: PEN1/SYP122 are required for papilla responses towards $B g h$. (A-B, $D-E)$ Accumulation of callose (A-B) or $\mathrm{H}_{2} \mathrm{O}_{2}$ (D-E) in response to Bgh attack (arrows) at non-penetrated attack sites. Bars $=10 \mu \mathrm{m}$. (C, F) Frequency of papillae in response to $\mathrm{Bgh}$ in non-penetrated cells as detected by staining for callose (C) or $\mathrm{H}_{2} \mathrm{O}_{2}(\mathrm{~F})$. (C, F) All values are mean $\pm \mathrm{SD}(\mathrm{n}=5$ leaves per genotype). Different letters indicate significantly different values at $P \leq 0.001$ estimated using logistic regression. 


\section{Figure 4}
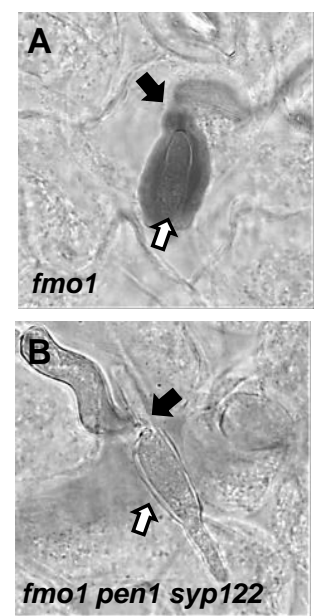
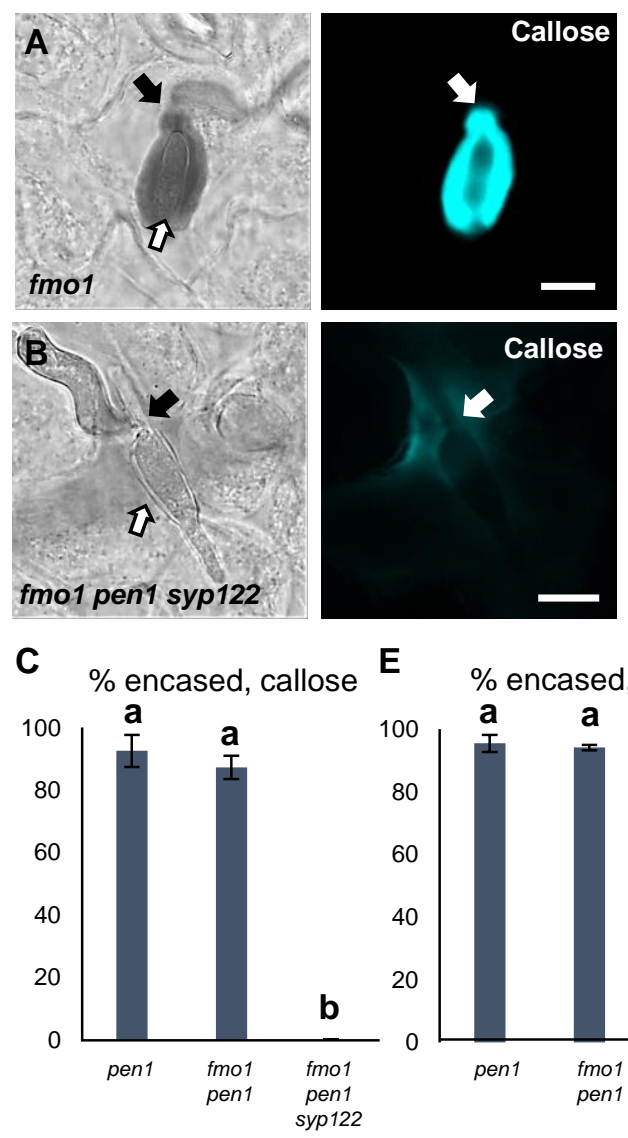
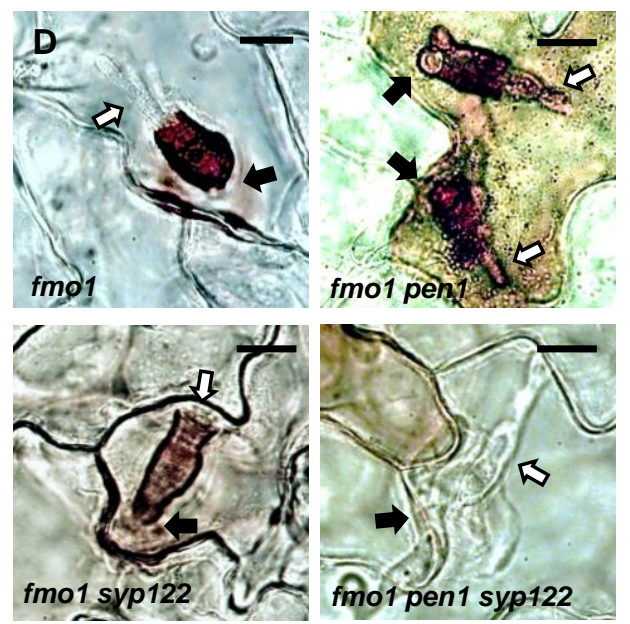

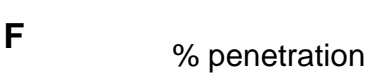

E $\%$ encased, $\mathrm{H}_{2} \mathrm{O}_{2}$
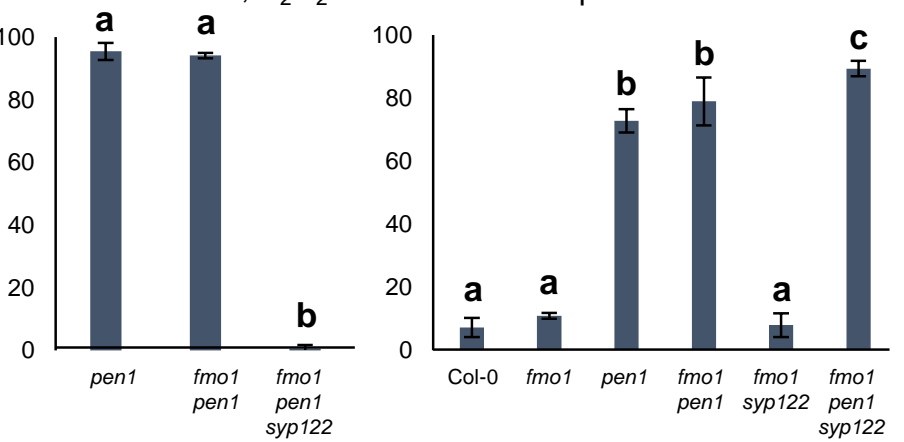

Figure 4: PEN1/SYP122 are required for encasement responses towards $\boldsymbol{B g h}$. (A-B, D) Accumulation of callose $(A-B)$ or $\mathrm{H}_{2} \mathrm{O}_{2}$ (D) in response to Bgh attack (arrows) at penetrated attack sites. Open arrows point to the developing IPS. Bars $=10 \mu \mathrm{m}$. (C, E) Frequency of encasements in response to $B g h$ in penetrated cells as detected by staining for callose (C) or $\mathrm{H}_{2} \mathrm{O}_{2}(\mathrm{E})$. (F) Frequency of penetrations by $B g h$. (C, E-F) All values are mean $\pm S D$ ( $n=5$ leaves per genotype). Different letters indicate significantly different values at $\mathrm{P} \leq 0.001$ estimated using logistic regression. 


\section{Figure 5}
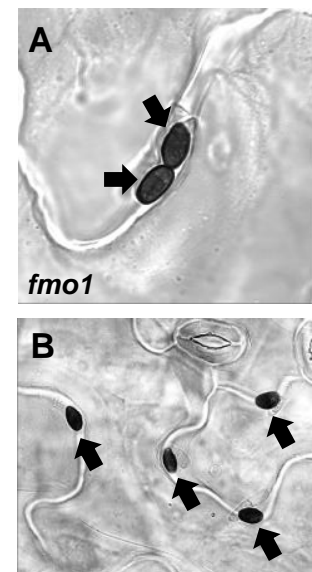

fmo1 pen1 syp122
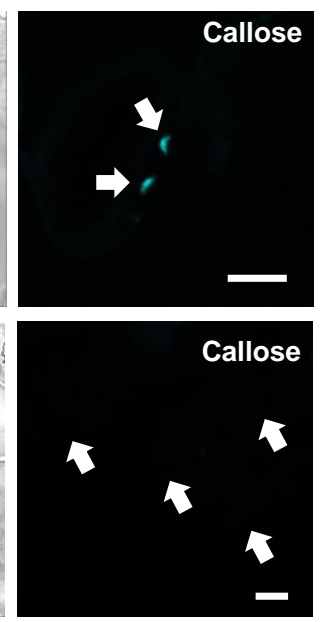

C

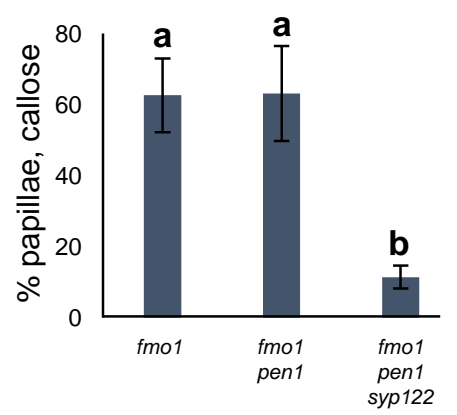

$\mathbf{F}$
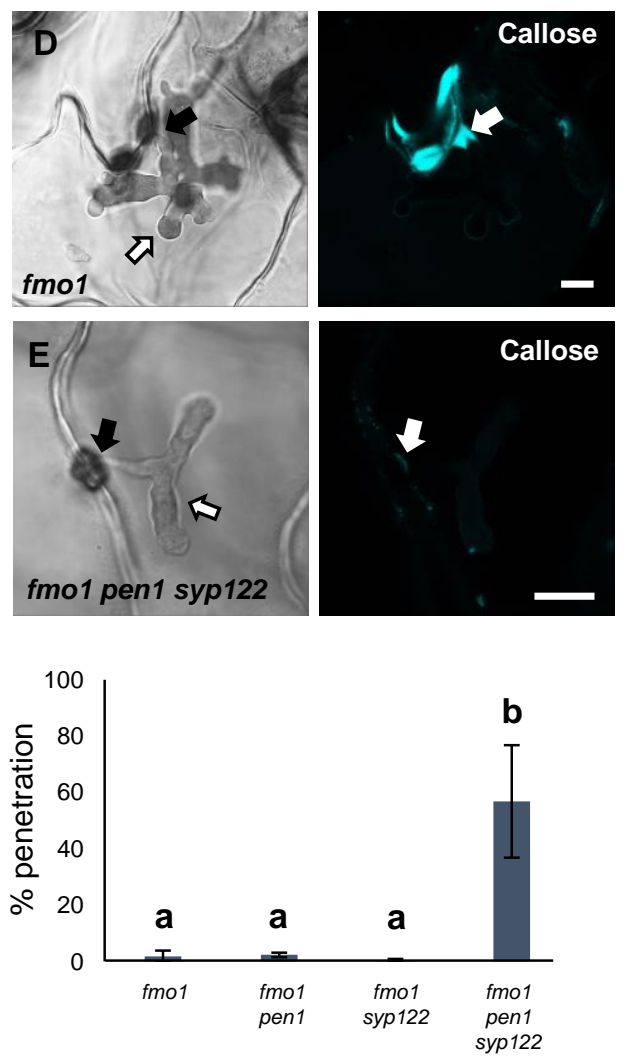

Figure 5: PEN1/SYP122 are required for pre-invasive immunity towards $C$. destructivum. ( $A, B$ and $D, E)$ Accumulation of callose in response to attack by melanized $C$. destructivum appressoria (arrows) at (A and $B$ ) non-penetrated and ( $D$ and $E$ ) penetrated attack sites. Open arrows point to the developing IPS. Bars $=10$ $\mu \mathrm{m}$. (C) Frequency of papillae in response to $C$. destructivum in non-penetrated cells. (F) Frequency of penetrations by $C$. destructivum. (C, F) All values are mean $\pm S D(n$ $=4$ leaves per genotype). Different letters indicate significantly different values at $P \leq$ 0.001 estimated using logistic regression. 


\section{Figure 6}
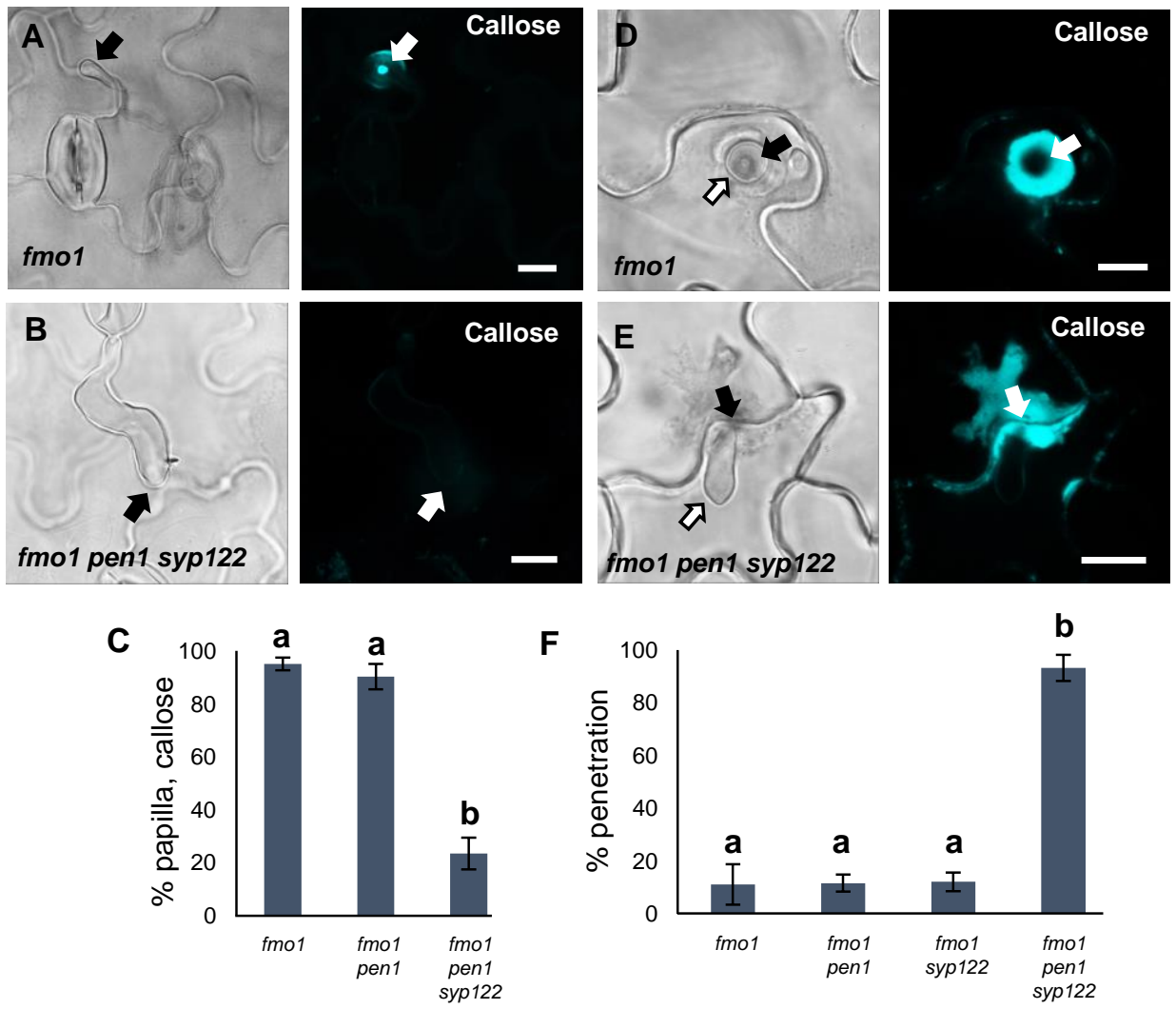

$\mathbf{F}$

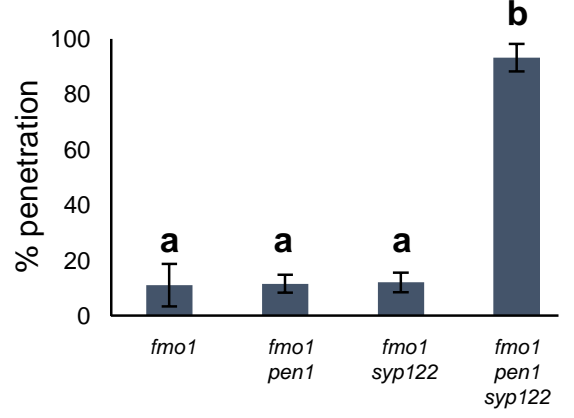

Figure 6: PEN1/SYP122 are required for pre-invasive immunity towards $\boldsymbol{P}$. infestans. (A-B, D-E) Accumulation of callose in response to $P$. infestans attack (arrows) at ( $A$ and $B$ ) non-penetrated and ( $D$ and $E$ ) penetrated attack sites. Open arrows point to the developing IPS. Bars $=10 \mu \mathrm{m}$. (C) Frequency of papillae in response to $P$. infestans in non-penetrated cells. (F) Frequency of penetrations by $P$. infestans. (C, F) All values are mean $\pm S D(n=4$ leaves per genotype). Different letters indicate significantly different values at $P \leq 0.001$ estimated using logistic regression. 


\section{Figure 7}
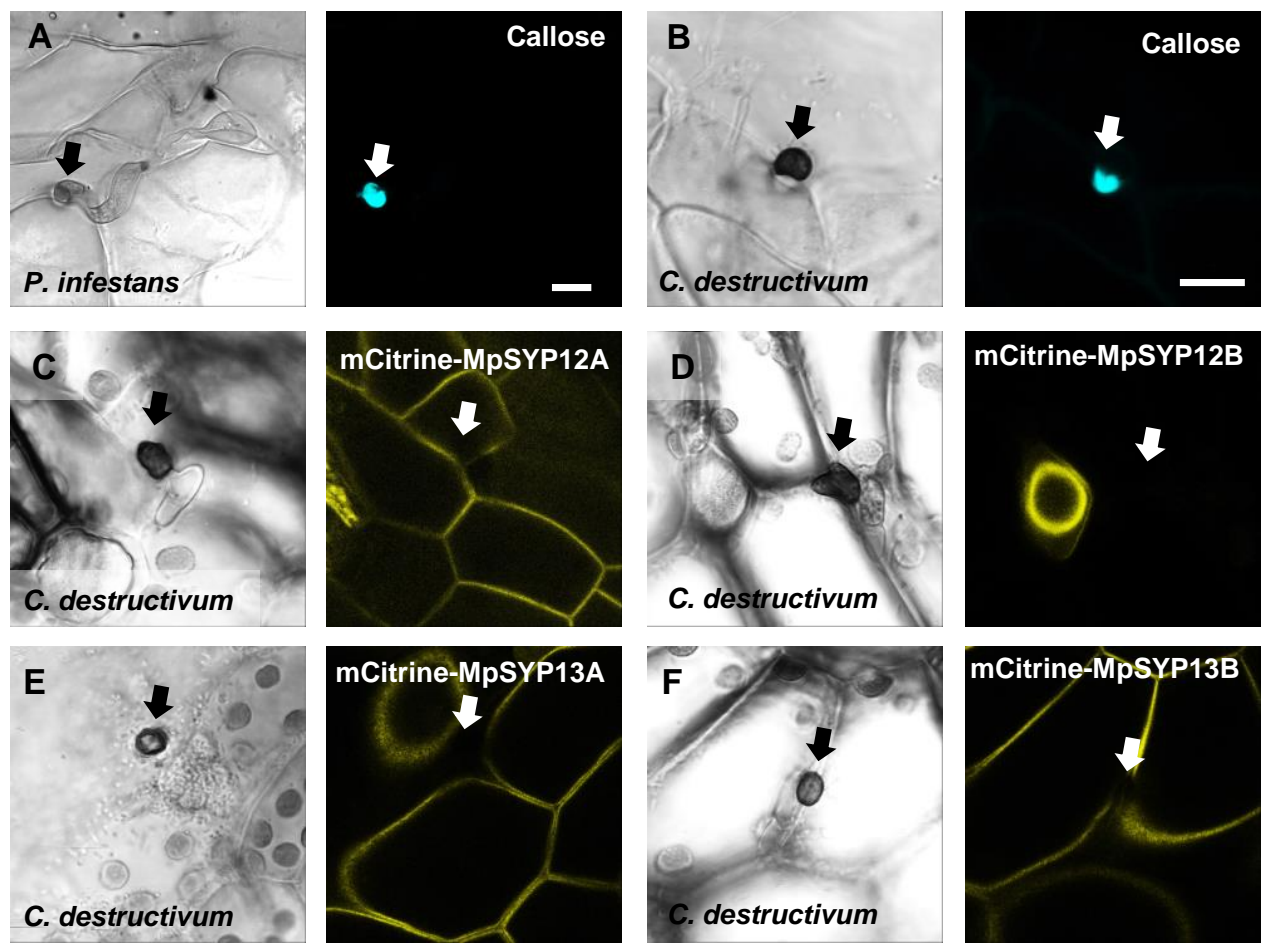

Figure 7. Responses in Marchantia polymorpha to filamentous pathogens. (AB) Accumulation of callose in Marchantia in response to attack (arrows) by (A) $P$. infestans or (B) $C$. destructivum in non-penetrated cells. Note that the frequency of $P$. infestans spores that attack a host-cell is very low. (C-F) mCitrine signal of MpSYPs in response to attack (arrows) by $C$. destructivum in non-penetrated cells. We did not observe any successful penetrations in Marchantia by $C$. destructivum. Bars $=10 \mu \mathrm{m}$. 


\section{Figure 8}
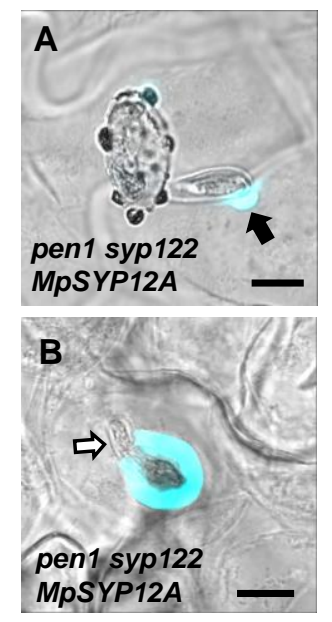

E

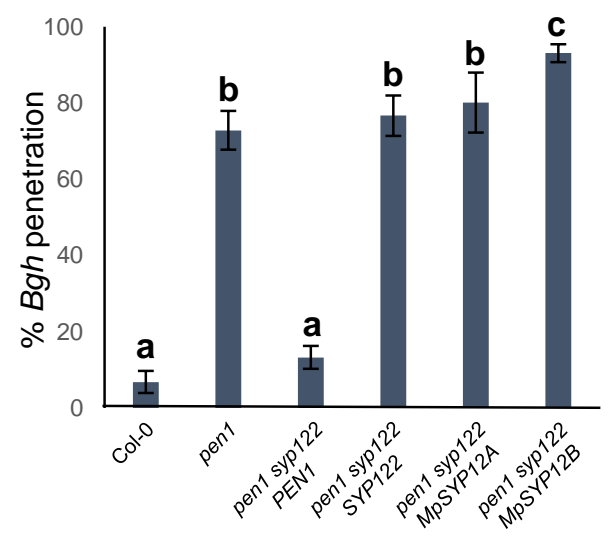

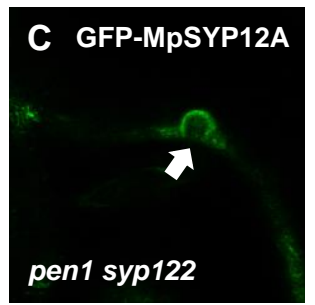
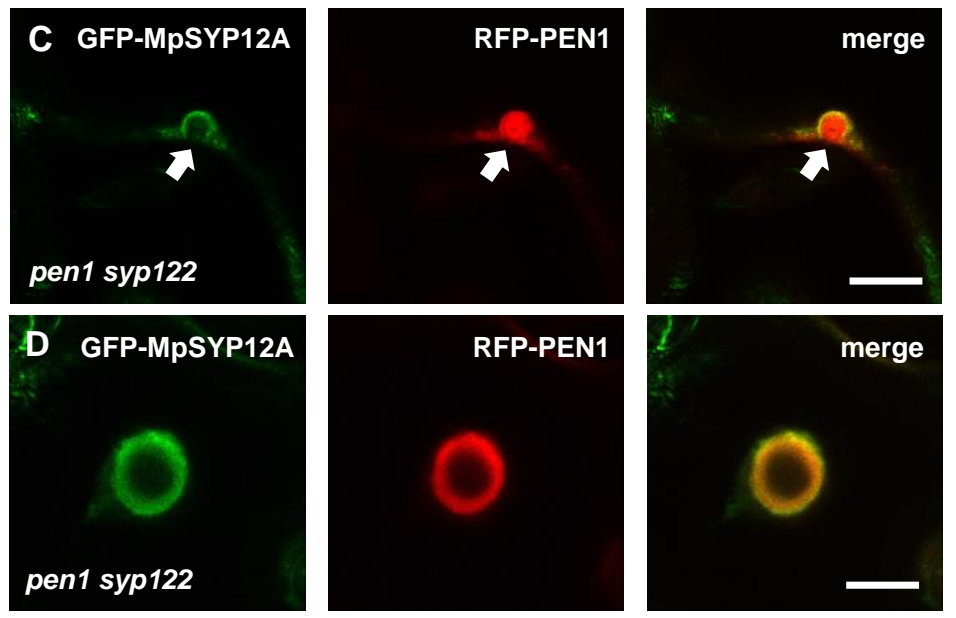

$\mathbf{F}$

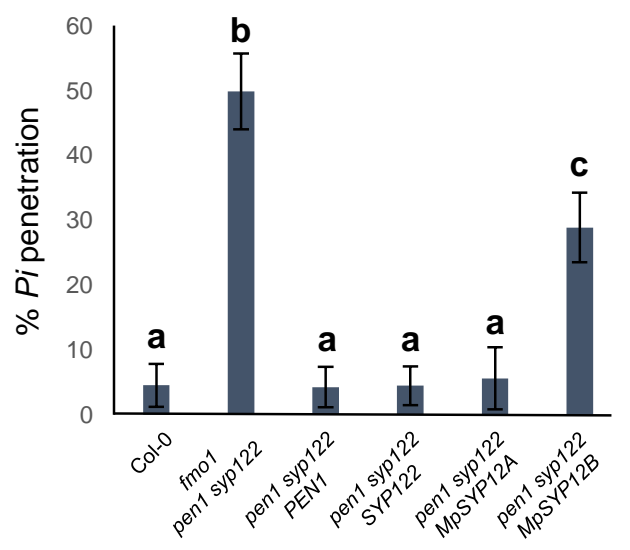

Figure 8: Marchantia syntaxins rescue papilla and encasement responses in Arabidopsis. (A, B) Accumulation of callose in response to attack (arrow) by Bgh in (A) non-penetrated- and (B) penetrated cells. Open arrow points to the developing IPS. (C, D) Localization of MpSYP12A and PEN1 in response to attack (arrows) by $B g h$ in $(C)$ non-penetrated- and $(D)$ penetrated cells. Bars $=10 \mu \mathrm{m}$. $(E, F)$ Frequency of penetration by (E) Bgh and (F) P. infestans. All values are mean $\pm S D(n=4$ leaves per genotype). Different letters indicate significantly different values at $P \leq 0.001$ estimated using logistic regression. 


\section{Figure 9}

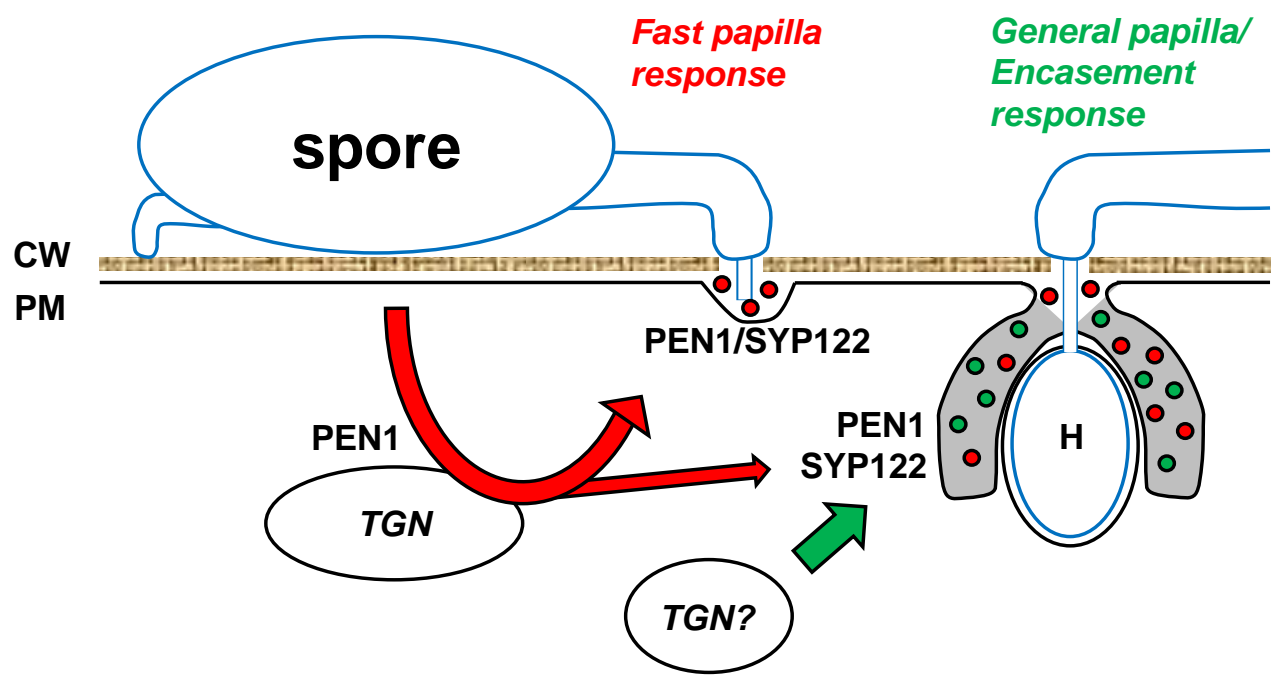

Fig. 9. Schematic model of immunity against filamentous pathogens mediated by PEN1 and SYP122. In response to attack by filamentous pathogens, cargo for the papilla/encasement is received at the plasma membrane (PM) by PEN1 or SYP122 and secreted in between the plant cell wall (CW) and the PM . For pre-invasive immunity against powdery mildew fungi, PEN1 is required at the TGN to enable recycling of cargo that facilitates a fast papilla response (shown in red). The slower, general papilla/encasement response (shown in green) does not require rapid recycling at the TGN using PEN1. Instead, this response likely involves a specialization of the conventional secretory pathway or an alternative recycling pathway where either PEN1 or SYP122 are required at the PM to receive vesicular cargo for the papilla/encasement formation. Likely, the fast papilla response pathway also contributes to formation of the encasement resulting in a mixture of cargo (such as exosomes and anti microbial metabolites) transported by both pathways. 


\section{Figure 1-figure supplement 1}

A

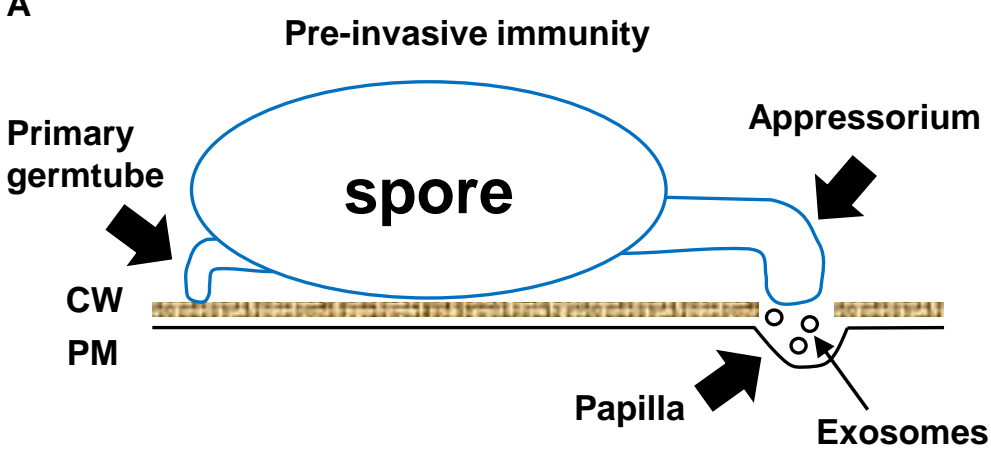

B
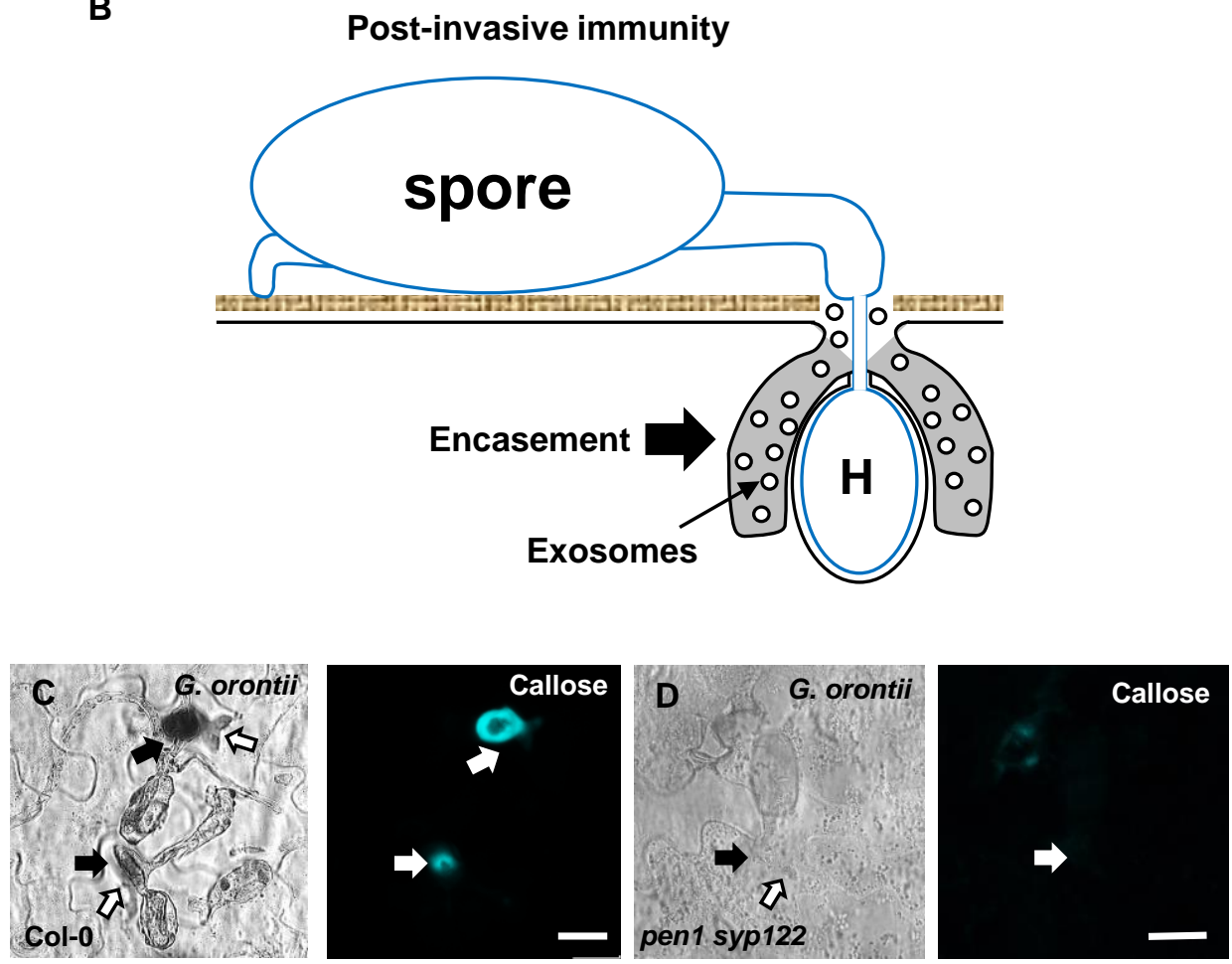

Figure 1-figure supplement 1. Pre- and post-invasive immunity. (A) Attack by non-adapted filamentous pathogens such as Bgh on Arabidopsis, is met by a localized apposition (papilla) formed between the plant cell wall (CW) and the plasma membrane (PM), containing callose, phenolic compounds, reactive oxygen species, and exosomes, that likely prevents penetration (Zeyen et al., 2002; Assaad et al., 2004; An et al., 2006). (B) Upon successful penetration, the host cell forms an encasement, similar in composition to the papilla, that eventually encloses the developing haustorium $(H)$ and prevents nutrient uptake. Similar to Bgh, spores of $C$. destructivum and $P$. infestans attempt to penetrate and form an intracellular pathogenic structure (IPS, haustoria, biotrophic hypae and infection vesicle, respectively). In the case of an ineffective encasement response, the host cell initiates a cell death response that prevents pathogen growth. (C-D) Accumulation of callose in response to successful penetration by $G$. orontii $(24 \mathrm{~h})$. Open arrows point to the developing IPS. Bars $=20 \mu \mathrm{m}$. 


\section{Figure 3-figure supplement 1}

A
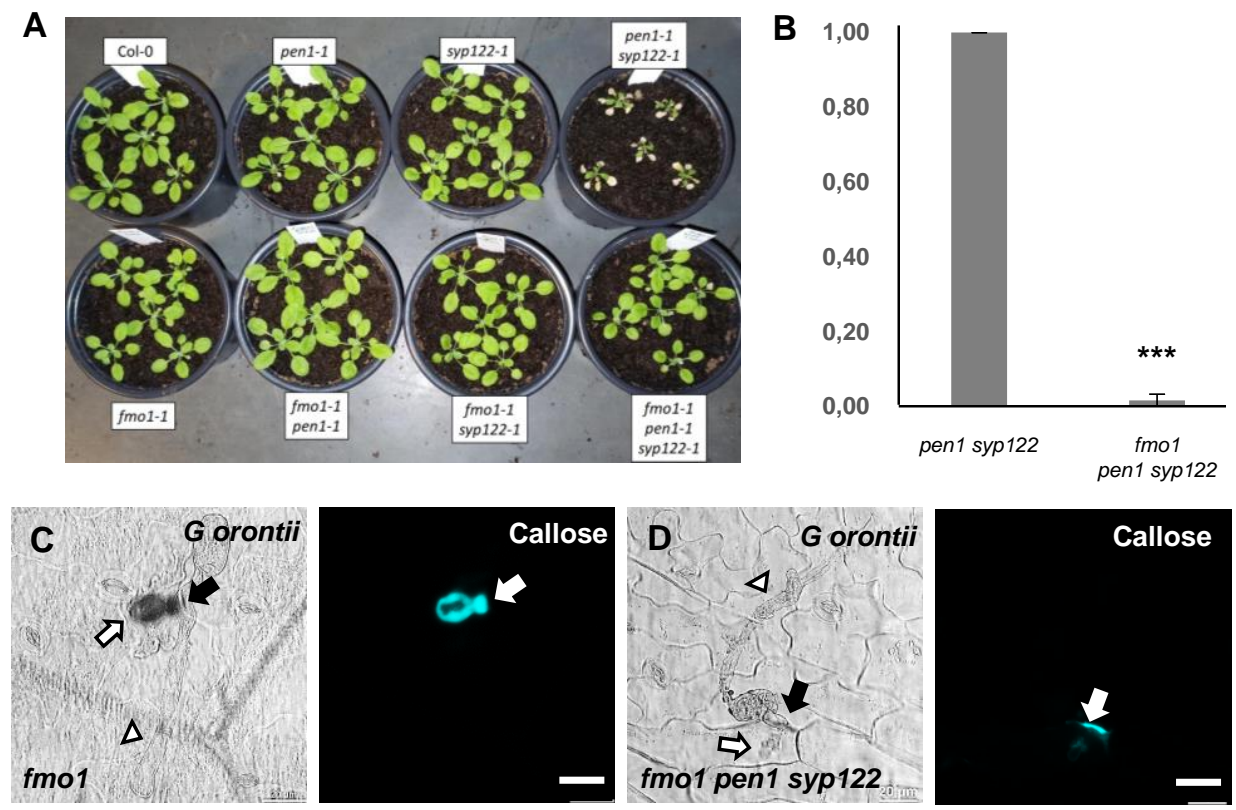

Figure 3-figure supplement 1. Loss of FMO1 attenuates pen1 syp122 autoimmunity. (A) Plants at 4 weeks, showing the growth phenotypes of the mutant lines used in these studies. (B) Relative transcript levels of PR1 in four week old plants. (F) Values are mean $\pm \mathrm{SD}(\mathrm{n}=3) .{ }^{* * *}, P<0.001$, Student's t test. (C-D) Accumulation of callose in response to G orontii- (48 h). Open- arrows and arrow heads point to the developing IPS and secondary hyphae, respectively. Bars $=20$ $\mu \mathrm{m}$. 


\section{Figure 3 -figure supplement 2}
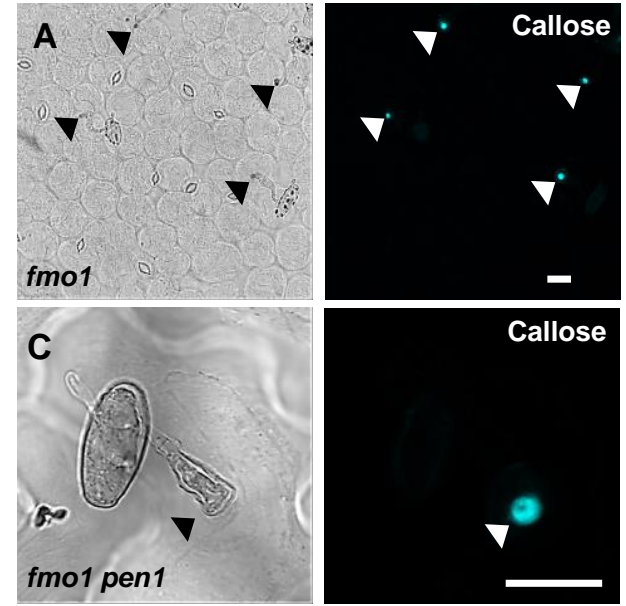
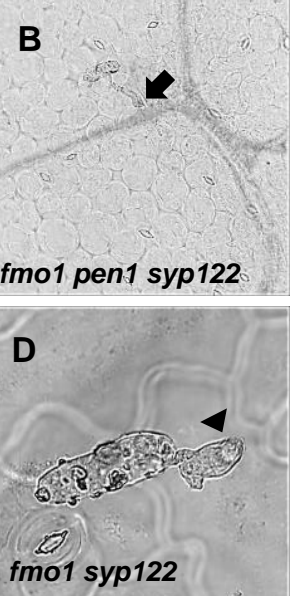
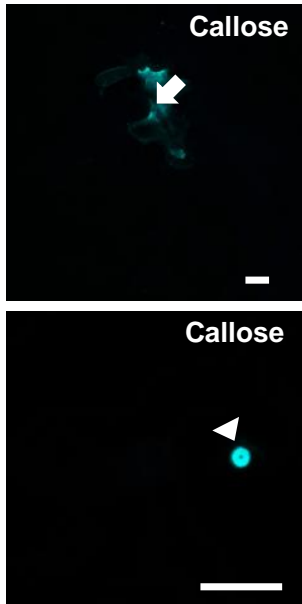

Figure 3-figure supplement 2. PEN1/SYP122 are required for papilla responses to Bgh. (A-D) Accumulation of callose in response to Bgh attack at non-penetrated (arrowheads) and penetrated (arrows) attack sites. Bars $=20 \mu \mathrm{m}$. 


\section{Figure 4-figure supplement 1}
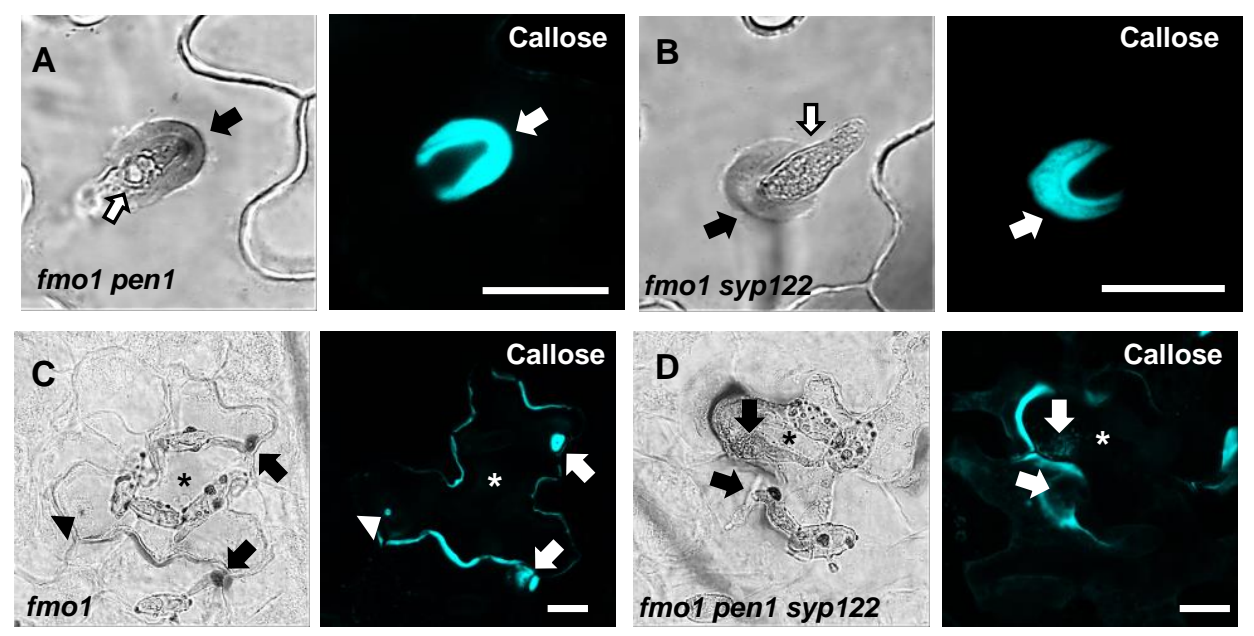

Figure 4-figure supplement 1. PEN1/SYP122 are required for encasement responses to Bgh. (A-D) Accumulation of callose in response to Bgh attack at nonpenetrated (arrowheads) and penetrated (arrows) attack sites. Open arrows point to the developing IPS. * marks cells with cell death response. Bars $=20 \mu \mathrm{m}$. 


\section{Figure 4-figure supplement 2}
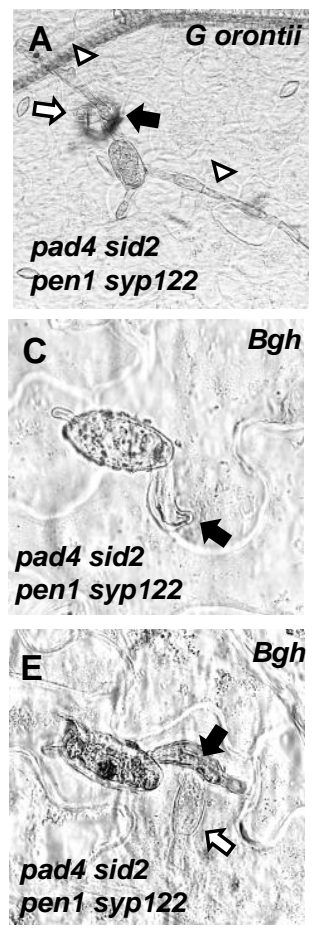
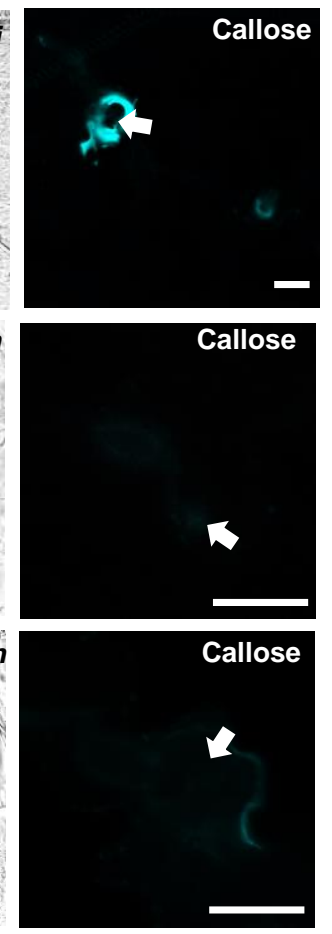
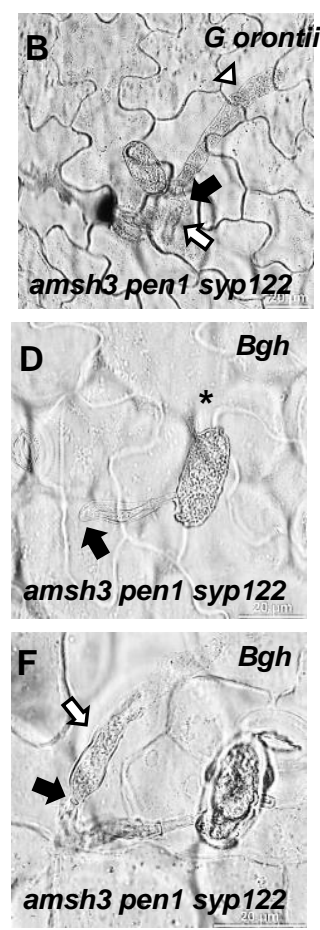
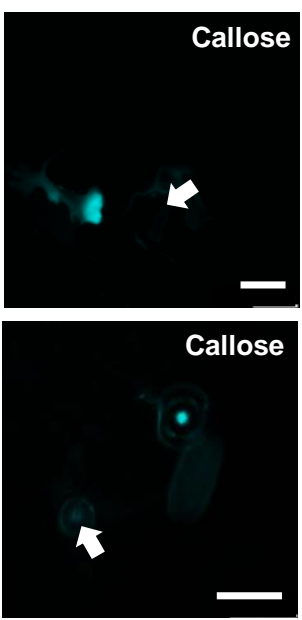

Callose

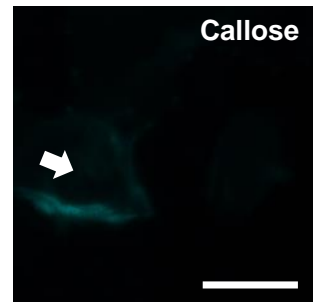

Figure 4-figure supplement 2. PEN1/SYP122 are required for papilla and encasement responses to Bgh. (A-F) Accumulation of callose in response to (A-B) G. orontii- and (C-F) Bgh (48 hours) attack at (C-D) non-penetrated and (A-B, E-F) penetrated attack sites (arrows). Open arrows point to the developing IPS. Openarrows and arrow heads point to the developing IPS and secondary hyphae, respectively. Bars $=20 \mu \mathrm{m}$. 


\section{Figure 5-figure supplement 1}
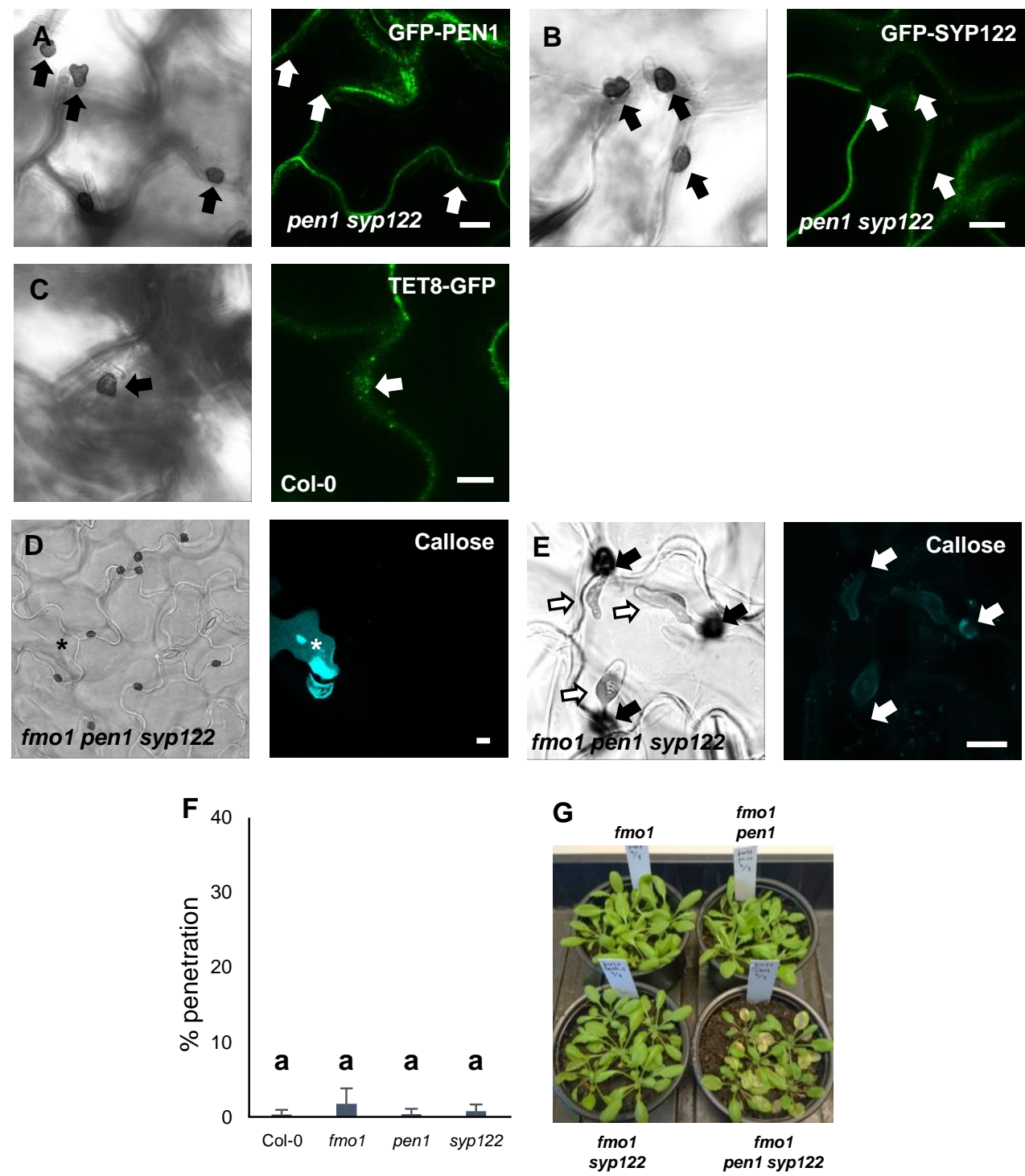

Figure 5-figure supplement 1. PEN1/SYP122 are required for pre-invasive immunity towards $\boldsymbol{C}$. destructivum. (A-C) Localisation of GFP-PEN1 (A), GFPSYP122 (B) and TET8-GFP (C) in response to attack by C. destructivum. (D-E) Accumulation of callose in response to attack by $C$. destructivum in (D) nonpenetrated cells and $(E)$ at penetration sites (arrows). Open arrows point to the developing IPS. * marks cell with cell death response. (F) Frequency of penetration by $C$. destructivum. $(\mathrm{G})$ Macroscopic phenotype at 5 dai with $C$. destructivum. Bars = $10 \mu \mathrm{m}$. (F) All values are mean $\pm S D(n=4$ leaves per genotype). Different letters indicate significantly different values at $P \leq 0.001$ estimated using logistic regression. 


\section{Figure 6-figure supplement 1}
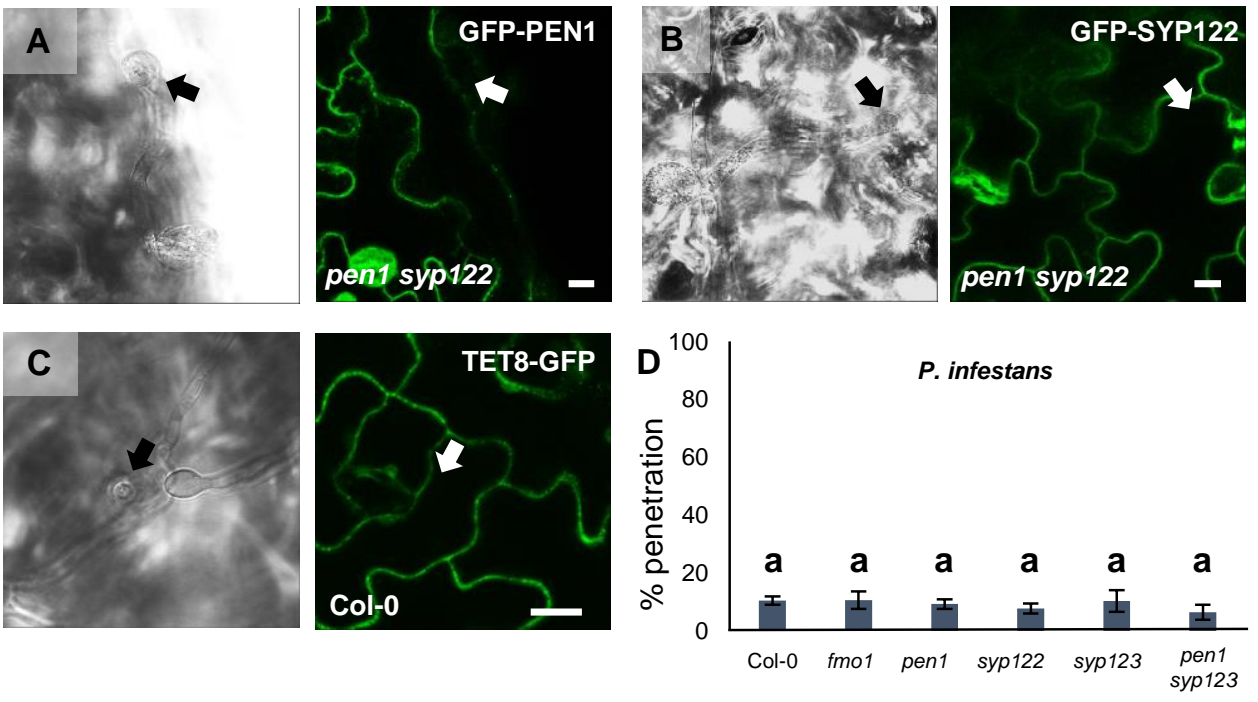

Figure 6-figure supplement 1. PEN1/SYP122 are required for pre-invasive immunity towards $\boldsymbol{P}$. infestans. (A-C) Localisation of GFP-PEN1 (A), GFP-SYP122 (B) and TET8-GFP (C) in response to attack by $P$. infestans. (D) Frequency of penetration by P.infestans. Bars $=10 \mu \mathrm{m}$. (D) All values are mean $\pm \mathrm{SD}(\mathrm{n}=4$ leaves per genotype). Different letters indicate significantly different values at $P \leq 0.001$ estimated using logistic regression. 


\section{Figure 7-figure supplement 1}
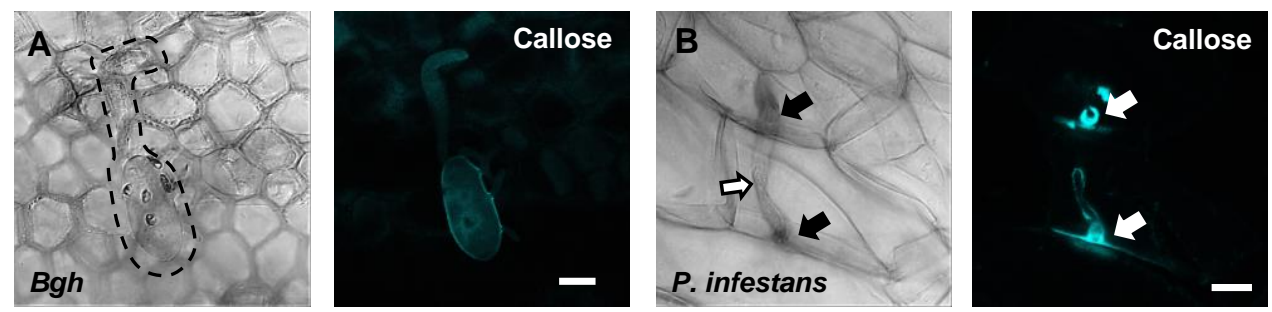

Figure 7-figure supplement 1. Responses in Marchantia polymorpha to filamentous pathogens. (A) On M. polymorpha, spores from Bgh (dotted line) were mis-differentiated with no or wrongly orientated appressoria that did not attack the host-cell. (B) Accumulation of callose in M. polymorpha in response to attack by $P$. infestans (arrows) in penetrated cells. Open arrow points to the developing IPS. Note that the frequency of $P$. infestans spores that attack a host-cell is very low. Bars $=10$ $\mu \mathrm{m}$. 


\section{Figure 8-figure supplement 1}

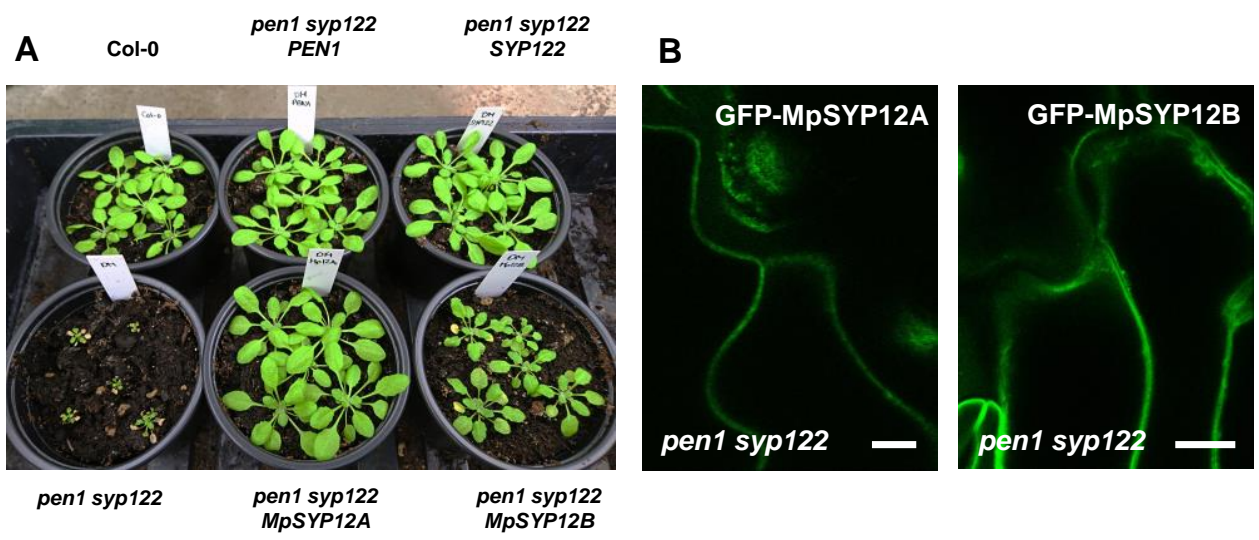

Figure 8-figure supplement 1. Marchantia syntaxins are functional in

Arabidopsis. (A) Plants at five weeks, expressing SYP12 clade members from either Arabidopsis or Marchantia polymorpha. (B) Localization of Marchantia SYP12 clade members in the epidermis of leaves from plants of four weeks. Bars $=10 \mu \mathrm{m}$. 


\section{Figure 8-figure supplement 2}

A
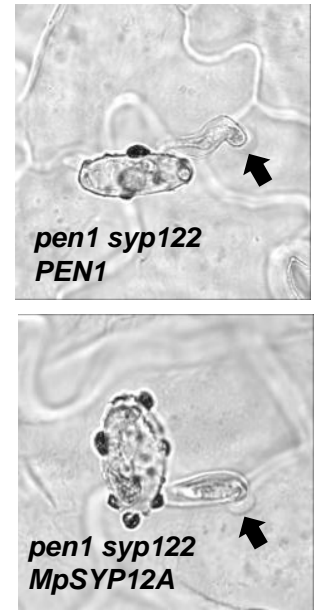

MpSYP12A
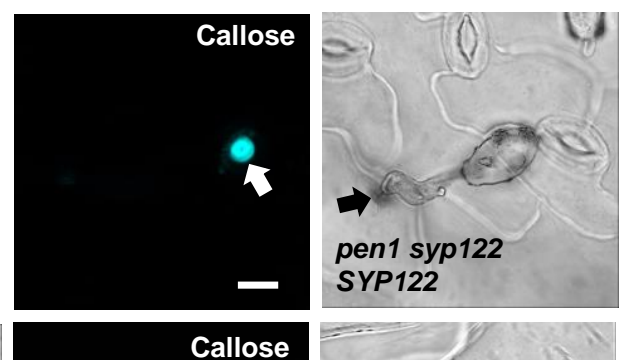

Callose
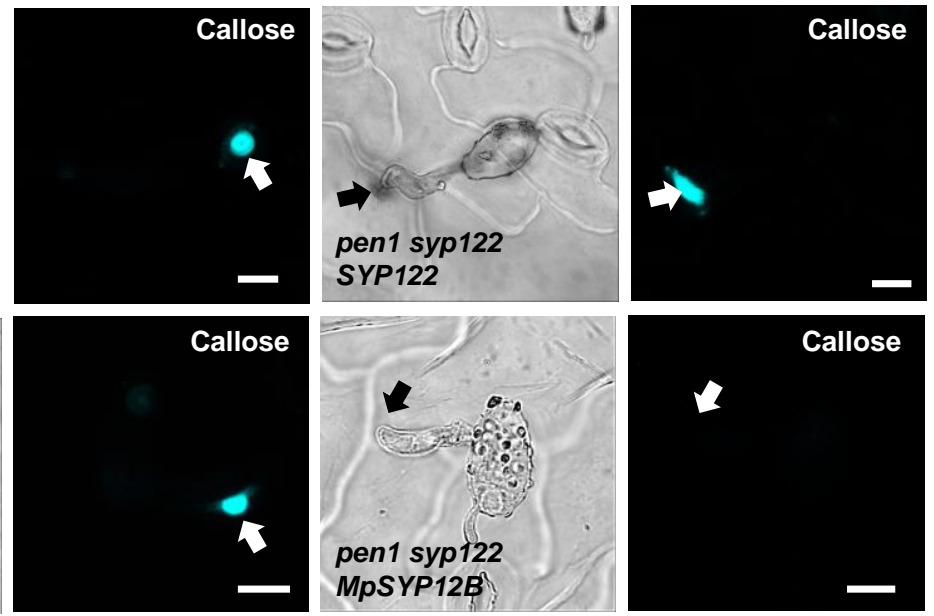

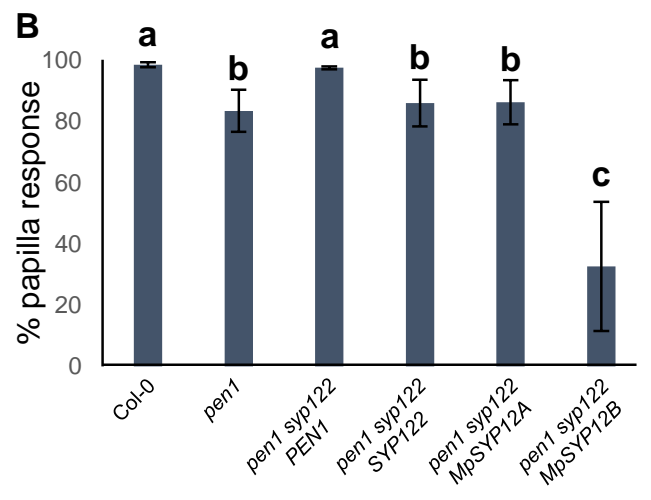

Figure 8-figure supplement 2. Marchantia syntaxins rescue papilla responses. (A) Accumulation of callose in response to Bgh attack at non-penetrated (arrows) attack sites. Bars $=10 \mu \mathrm{m}$. (B) Frequency of papillae in response to $B g h$ in nonpenetrated cells. All values are mean $\pm S D$ ( $n=5$ leaves per genotype). Different letters indicate significantly different values at $P \leq 0.001$ estimated using logistic regression. 


\section{Figure 8-figure supplement 3}

A
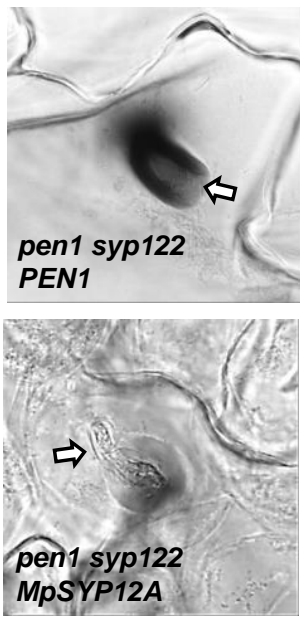
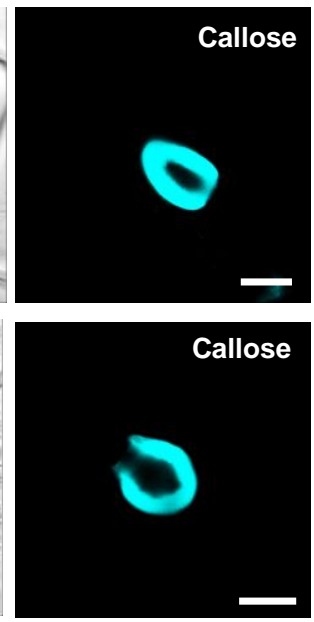
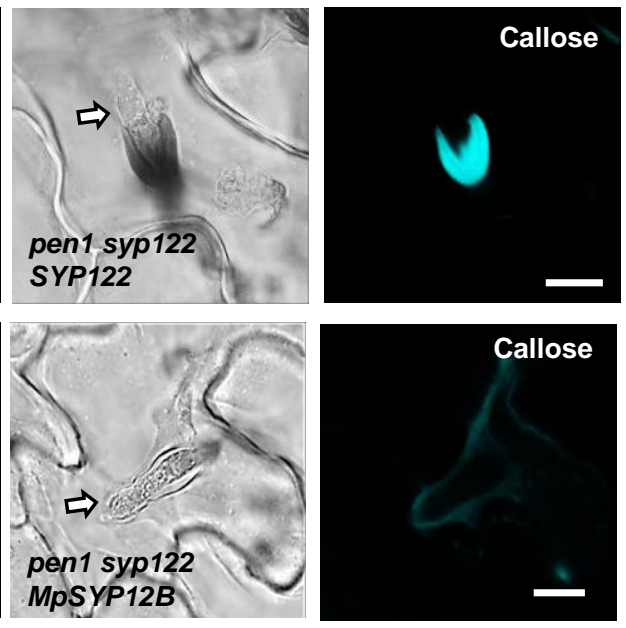

B

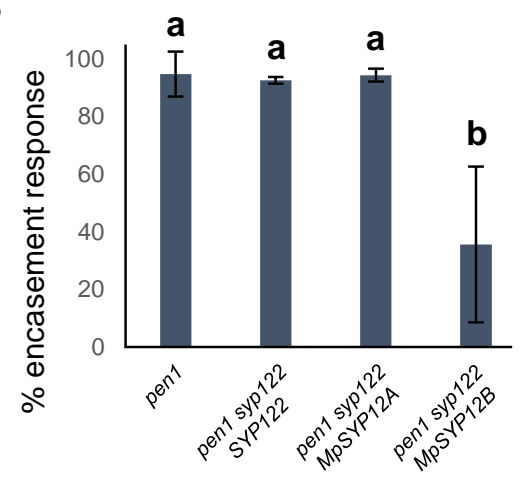

Figure 8-figure supplement 3. Marchantia syntaxins rescue encasement responses. (A) Accumulation of callose in response to Bgh attack at successful penetration sites. Open arrows point to the developing IPS. Bars $=10 \mu \mathrm{m}$. (B) Frequency of encasements in response to $\mathrm{Bgh}$ haustoria in penetrated cells. All values are mean $\pm S D(n=5$ leaves per genotype). Different letters indicate significantly different values at $P \leq 0.001$ estimated using logistic regression. 


\section{Figure 8-figure supplement 4}
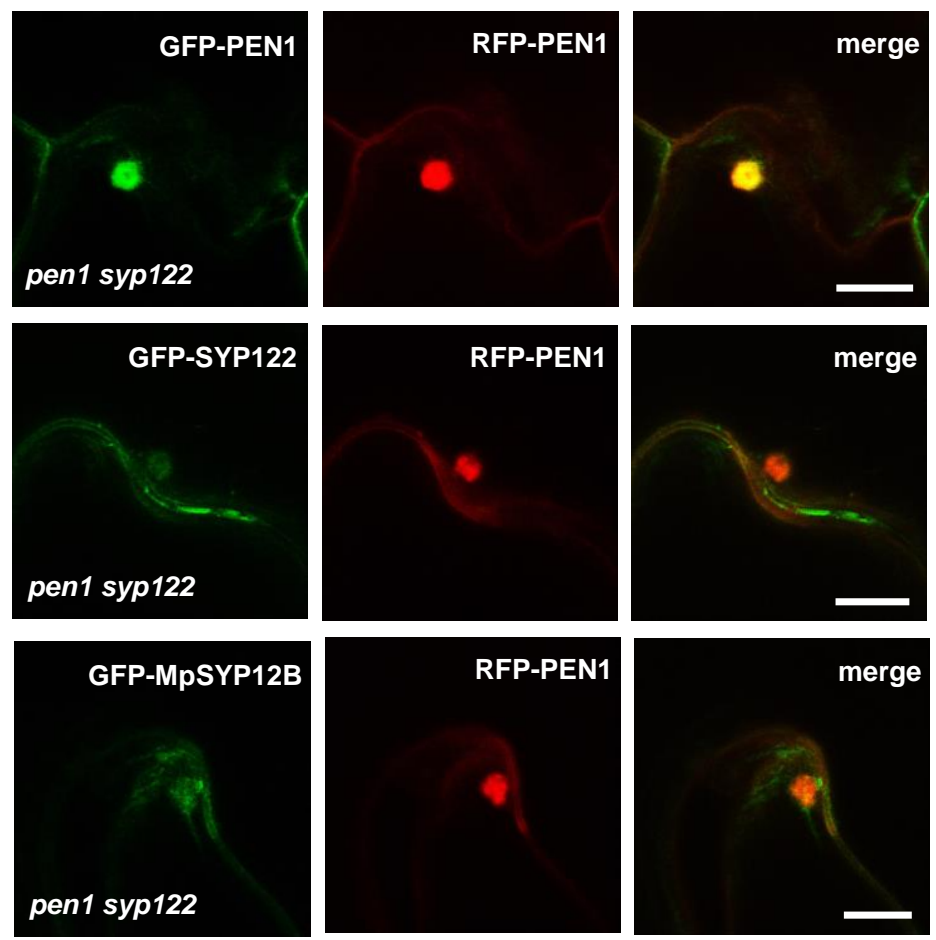

Figure 8-figure supplement 4. Localization of SYP12 clade members at Bgh attack sites. Comparative papilla localization of SYP12 members from Arabidopsis or Marchantia in response to attack by $B g h$ in non-penetrated cells. Bars $=10 \mu \mathrm{m}$. 


\section{Figure 8-figure supplement 5}
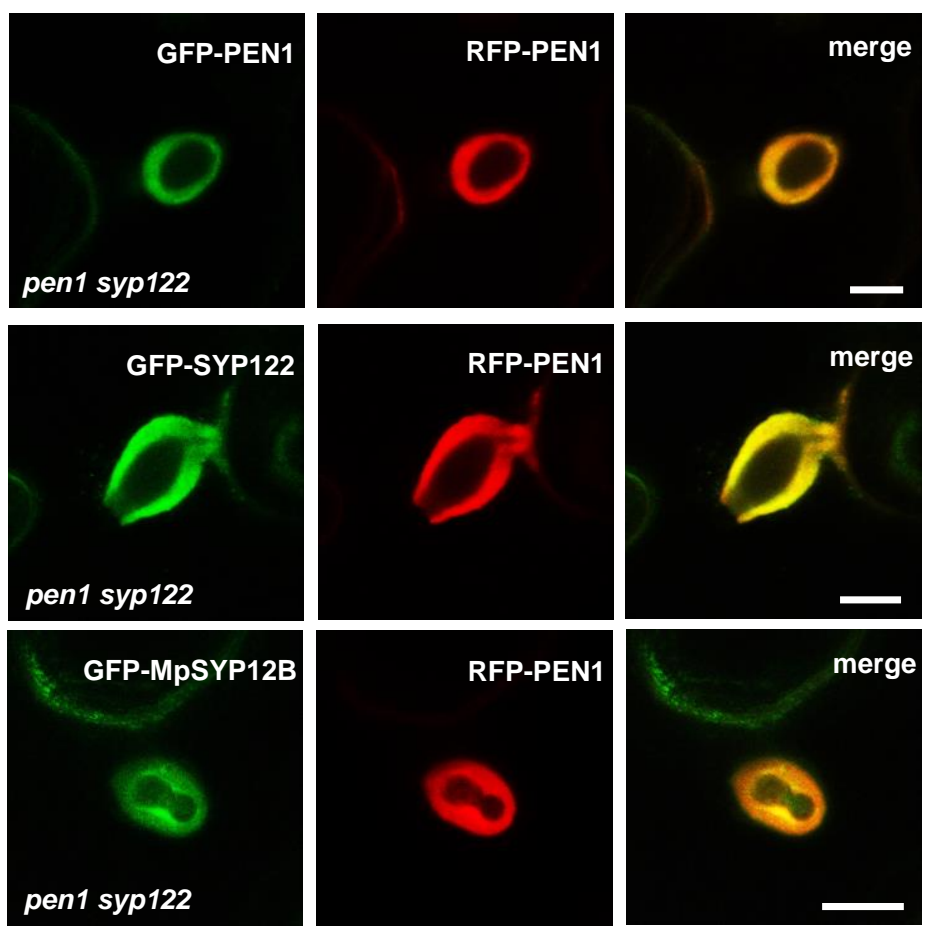

Figure 8-figure supplement 5. Localization of SYP12 clade members at $\mathbf{B g h}$ penetration sites. Comparative encasement localization of SYP12 members from

Arabidopsis or Marchantia in response to haustoria by $\mathrm{Bgh}$ in penetrated cells. Bars $=10 \mu \mathrm{m}$. 


\section{Figure 8-figure supplement 6}

A

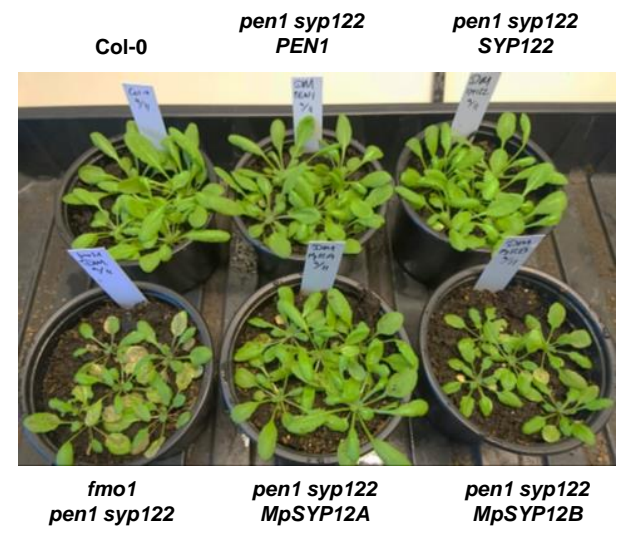

C

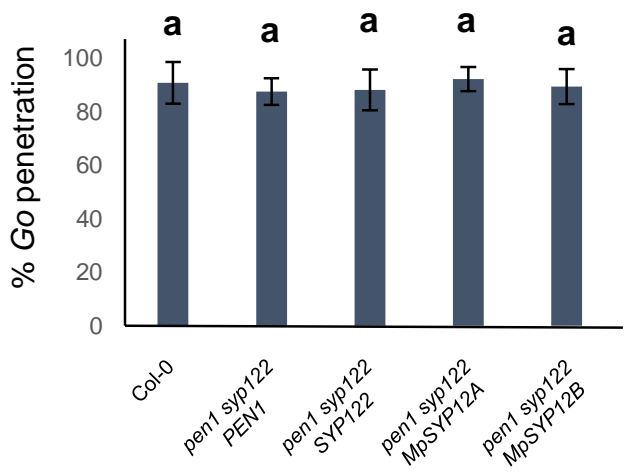

B
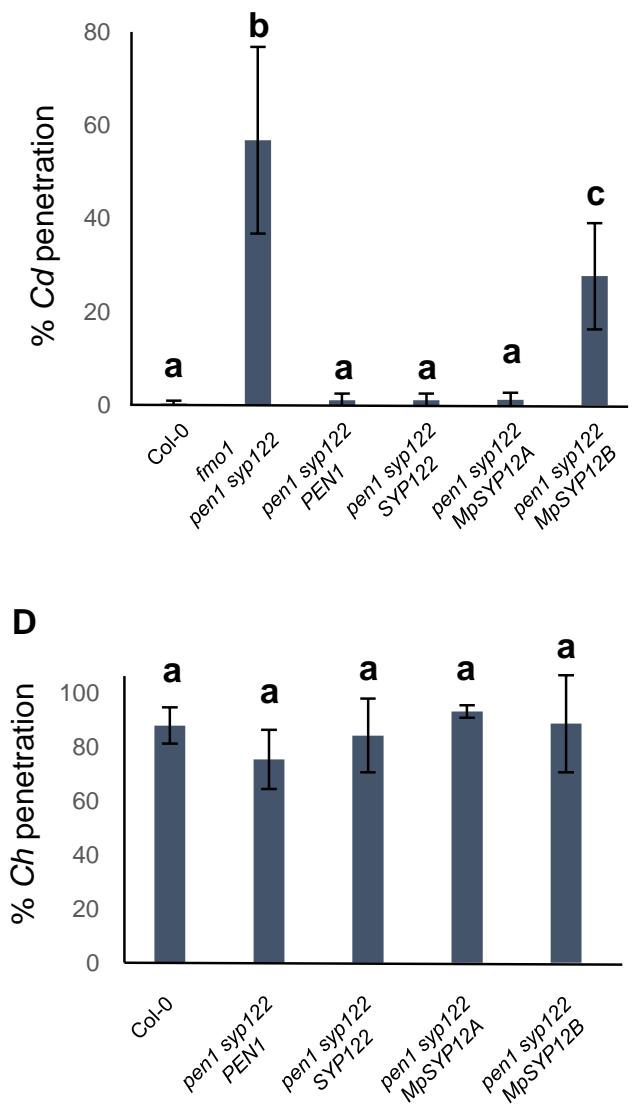

Figure 8-figure supplement 6. Marchantia SYP12s restore immunity in Arabidopsis towards $C$. destructivum. (A) Macroscopic phenotype at 5 dai with $C$. destructivum. (B-D) Frequency of penetration by C. destructivum (B), G. orontii (C) and $C$. higginsianum (D). (B-D) All values are mean $\pm S D(n=4$ leaves per genotype). Different letters indicate significantly different values at $P \leq 0.001$ estimated using logistic regression. 


\section{Figure 8-figure supplement 7}
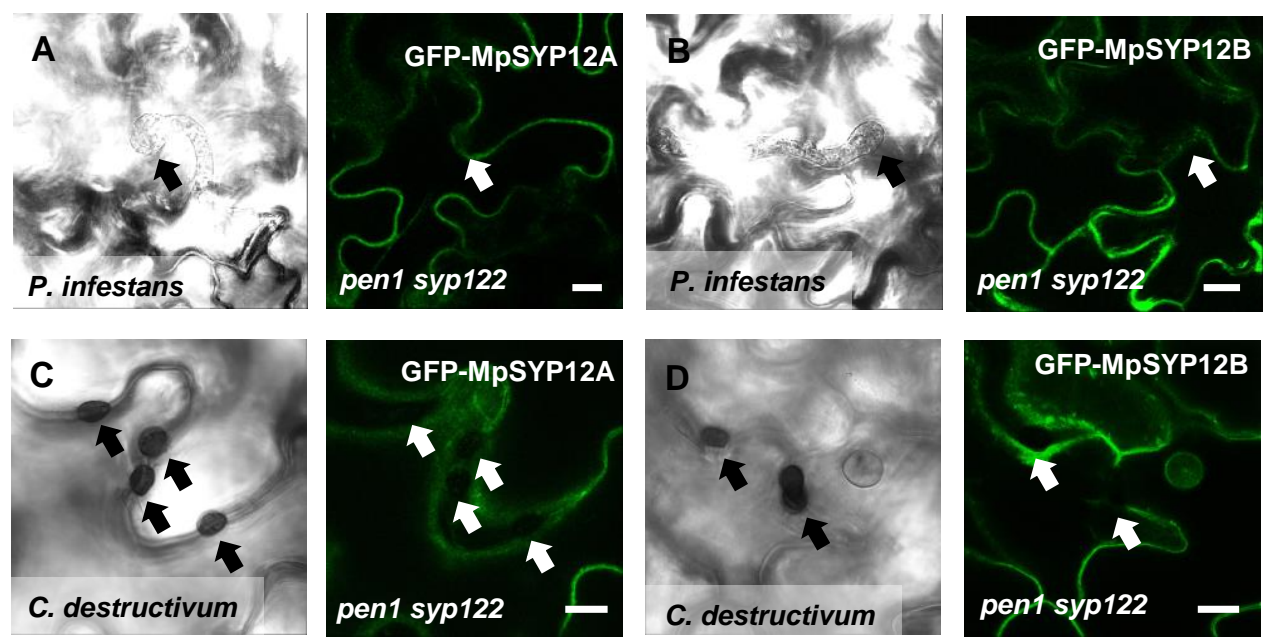

Figure 8-figure supplement 7. Localization of Marchantia SYP12 clade members at attack sites. (A-D) Localization of GFP-MpSYP12A (A, C) and GFP-MpSYP12A $(B, D)$ in response to attack by $P$. infestans $(A-B)$ and $C$. destructivum $(C-D)$ in nonpenetrated cells. Bars $=10 \mu \mathrm{m}$. 